\title{
Topological Analysis and Charge Density Studies of an $\alpha$-Diimine Macrocyclic Complex of Cobalt(II) - A Combined Experimental and Theoretical Study
}

\author{
Jey-Jau Lee, Gene Hsiang Lee, and Yu Wang*[a]
}

\begin{abstract}
A combined experimental and theoretical study of the paramagnetic $\quad\left[\mathrm{Co}^{\mathrm{II}}\left(\mathrm{C}_{12} \mathrm{H}_{20} \mathrm{~N}_{8}\right)\left(\mathrm{H}_{2} \mathrm{O}\right)_{2}\right] \cdot 2 \mathrm{ClO}_{4}$ complex was made on the basis of the electron density distribution and topological analysis. Accurate single-crystal diffraction data were measured on a suitable crystal with $\mathrm{Mo}_{\mathrm{K} \alpha}$ radiation at $125 \mathrm{~K}$. The $\mathrm{Co}^{\mathrm{II}}$ ion is coordinated in a square bipyramidal fashion with four imino nitrogen atoms at the equatorial plane and two water molecules at the axial positions. The hydrogen-bonding interaction at $125 \mathrm{~K}$ between the coordinated water molecule and the $\mathrm{ClO}_{4}^{-}$ ion makes the space group different from that at $298 \mathrm{~K}$. Parallel MO calcu-
\end{abstract}

lations were made at UHF and DFT/ UB3LYP. The agreement between experiment and theory is reasonably good. The chemical bonding characterization is presented in terms of the topological properties associated with bond critical points and the natural bond orbital (NBO) analysis as well. The $\mathrm{Co}-\mathrm{N}_{\text {imino }}$ and $\mathrm{Co}-\mathrm{O}_{\text {water }}$ bonds are dative bonds, where the lone-pair electrons of $\mathrm{N}$ or $\mathrm{O}$ serve as a $\sigma$-donor; however, a certain covalent character is identified in the

Keywords: charge density $\cdot$ cobalt • hydrogen bonds • macrocyclic ligands $\cdot$ topological analysis
$\mathrm{Co}-\mathrm{N}_{\text {imino }}$ bond. A delocalized $\mathrm{C}-\mathrm{N}$, $\mathrm{N}-\mathrm{N} \pi$-bond model is proposed. The $\mathrm{d}$-orbital energies of $\mathrm{Co}$ in this complex are such that $E\left(\mathrm{~d}_{x z}\right) \approx E\left(\mathrm{~d}_{y z}\right) \approx E\left(\mathrm{~d}_{x^{2}-y^{2}}\right)<$ $E\left(\mathrm{~d}_{z^{2}}\right)<E\left(\mathrm{~d}_{x y}\right)$; notice that $\mathrm{d}_{x y}$ and $\mathrm{d}_{z^{2}}$ are $\mathrm{d}_{\sigma}$ orbitals in this case. The $\mathrm{Co}^{\mathrm{II}}$ ion is in a low-spin $\mathrm{d}^{7}$ state with the singly occupied $\mathrm{d}_{z^{2}}$ orbital. The asphericity in electron density at $\mathrm{Co}$ and $\mathrm{Cl}$ nuclei is nicely demonstrated by the Laplacian of electron density. The envelope plot of the isovalue Laplacian surface around the nucleus gives the exact shape of such asphericity. The isovalue Laplacian surfaces of these two nuclei show significantly different VSCC character in both experimental and theoretical results.

\section{Introduction}

The macrocyclic tetraimino ligand $\mathrm{C}_{10} \mathrm{H}_{20} \mathrm{~N}_{8}, 2,3,9,10$-tetramethyl-1,4,5,7,8,11,12,14-octaazacyclotetradeca-1,3,8,10-tetraene is normally observed as a square planar tetradentate ligand. ${ }^{[1]}$ This macrocyclic ligand is often coordinated to a divalent $3 \mathrm{~d}$ transition element like $\mathrm{Fe}^{\mathrm{II}}$, $\mathrm{Co}^{\mathrm{II}}, \mathrm{Ni}^{\mathrm{II}}$, or $\mathrm{Cu}^{\mathrm{II}}$. However these complexes could also be square-pyramidal or octahedral with additional axial ligands..$^{[1,2]}$

These complexes should play a key biological role since they are similar to those found in natural biosystems, such as metalloporphyrins, vitamin $\mathrm{B}_{6}$, or metal-chlorophyll. ${ }^{[3,4]}$ It would be interesting to use this transition metal complex as a model compound to mimic biological systems. There are many stable divalent cobalt complexes of tetradentate Schiff bases which are potential model systems for oxygen-binding

[a] Prof. Dr. Yu. Wang, Dr. J.-J. Lee, G. H. Lee

Department of Chemistry, National Taiwan University Taipei (Taiwan)

Fax: (+886) 2-23636359

E-mail: yuwang@xtal.ch.ntu.edu.tw

Supporting information for this article is available on the WWW under http://www.wiley-vch.de/home/chemistry/ or from the author. biomolecules, where molecular oxygen can be absorbed reversibly under certain conditions. ${ }^{[5]}$ The d-orbital energies and electronic structures of some $\mathrm{Co}^{\mathrm{II}}$ complexes have been characterized in detail on the basis of single-crystal ESR measurement and simulation. ${ }^{[5 b]}$ There is still controversy over the electronic configuration of the $\mathrm{Co}^{\mathrm{II}}$ ion in the squareplanar case as to whether the unpaired electron is in the $d_{z^{2}}$ $\left({ }^{2} \mathrm{~A}_{1}\right)$ or the $\mathrm{d}_{x y}\left({ }^{2} \mathrm{~B}_{1}\right)$ orbital (state). When one axial ligand is present, it is believed that the unpaired electron should be in the $d_{z^{2}}\left({ }^{2} A_{1}\right)$ orbital.

Studies $^{[6-8]}$ of a series of $\left[\mathrm{M}\left(\mathrm{C}_{10} \mathrm{H}_{20} \mathrm{~N}_{8}\right)\right]^{2+}$ compounds provide an interesting comparison of the ligand-field characteristics of such tetraimino macrocyclic ligands. Four imino-N centers in the equatorial plane usually exert a strong ligand field toward the metal ion. The conjugated $\pi$-orbital system of the ligand (Scheme 1) incorporated with the suitable d-orbital of the metal ion gives rise to a low-spin state in the central metal ion. ${ }^{[7,9]}$

The electron density distribution is useful for chemical bond characterization. The asphericity in electron density near the metal nucleus could give direct evidence on the effect of chemical bonding owing to the crystal field splitting. We have therefore carried out a combined experimental and 


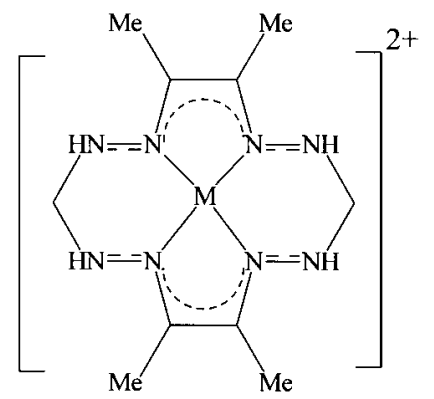

Scheme 1. The partial double bond system of the macrocyclic tetraimino tetraene ligand.

theoretical study of the electron density distribution of the cobalt(II) octaazabisdiimine macrocyclic complex ${ }^{[1,2]}$ in order to better understand the chemical bonding of this complex.

\section{Results and Discussion}

Structure: The molecular structure with thermal ellipsoids of the title complex cation at $125 \mathrm{~K}$ is depicted in Figure 1a. The hydrogen atoms are omitted for clarity. The exact molecular symmetry is $C_{\mathrm{i}}$. However, the geometry of the cation is

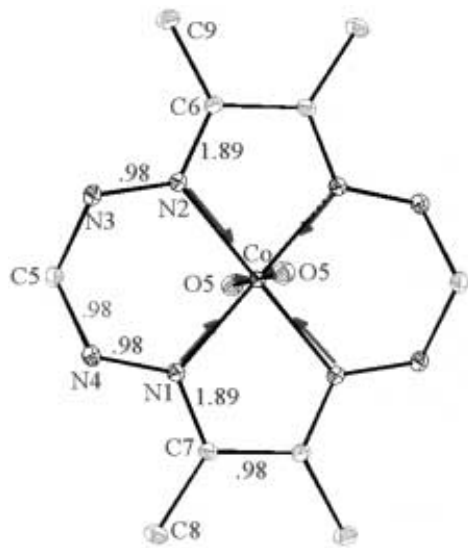

a)

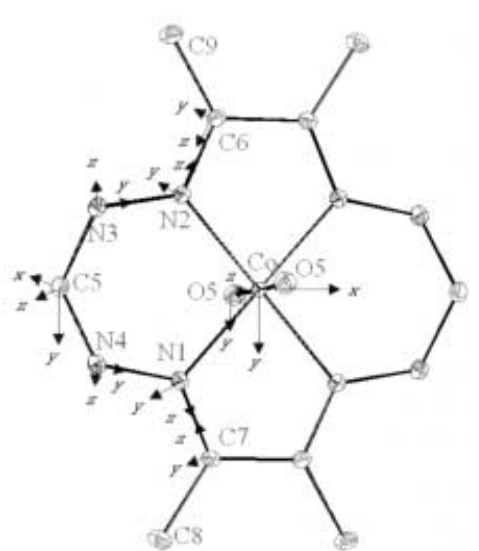

Figure 1. a) Molecular drawing of cobalt complex cation with $30 \%$ probability in thermal ellipsoids and bond order at $125 \mathrm{~K}$; the heavy arrows represent dative bonds; b) the choice of local Cartesian axes for each atom. essentially the same as that at room temperature, which has higher symmetry, $C_{2 \mathrm{~h}}$. Atomic coordinates and equivalent isotropic displacement parameters obtained by full-matrix least-squares refinements based on spherical and multipole models both at $298 \mathrm{~K}$ and at $125 \mathrm{~K}$ are given in Tables 1 and 2 , respectively. Selected bond lengths and angles are listed in Table 3. The coordination geometry around the Co ion is a tetragonally distorted octahedron owing to the Z-out JahnTeller distortion. ${ }^{[10]}$ Four imino nitrogen atoms are in the equatorial plane and two oxygen atoms of water molecules

Table 1. Atomic fractional coordinates and $B_{\text {eq }}$ values $\left[\AA^{2}\right]$ of non-hydrogen atoms at $298 \mathrm{~K}$ in space group Cmca.

\begin{tabular}{llllc}
\hline Atom & $x$ & $y$ & $z$ & $B_{\mathrm{eq}}^{[\mathrm{a}]}$ \\
\hline Co & $1 / 2$ & 0 & 0 & $2.28(4)$ \\
O5 & $1 / 2$ & $0.0432(2)$ & $0.2037(4)$ & $3.8(2)$ \\
$\mathrm{N} 1$ & $0.6240(3)$ & $-0.0672(2)$ & $0.0441(3)$ & $2.5(1)$ \\
$\mathrm{N} 4$ & $0.6034(3)$ & $-0.1376(2)$ & $0.1057(3)$ & $3.2(1)$ \\
C7 & $0.7258(3)$ & $-0.0390(2)$ & $0.0300(3)$ & $2.7(1)$ \\
C5 & $1 / 2$ & $-0.1765(3)$ & $0.0619(6)$ & $3.4(3)$ \\
C8 & $0.8336(4)$ & $-0.0778(3)$ & $0.0704(4)$ & $4.1(2)$ \\
Cl & $3 / 4$ & $0.31894(8)$ & $1 / 4$ & $3.71(7)$ \\
O2 & $3 / 4$ & $0.4009(3)$ & $1 / 4$ & $7.1(3)$ \\
O3 & $0.7693(6)$ & $0.2815(2)$ & $0.1426(4)$ & $11.4(4)$ \\
O4[b] & $0.6221(7)$ & $0.3154(5)$ & $0.229(1)$ & $8.5(5)$ \\
\hline
\end{tabular}

[a] $B_{\text {eq }}=\left(8 \pi^{2} / 3\right) \sum_{i} \Sigma_{j} U_{i j} \mathrm{a}_{i}^{*} \mathrm{a}_{j}^{*} \mathrm{a}_{i} \mathrm{a}_{j}$. [b] Occupancy is 0.5 .

Table 2. Atomic fractional coordinates and $B_{\text {eq }}$ values $\left[\AA^{2}\right]$ of non-hydrogen atoms at $125 \mathrm{~K}$ in space group Pbca: first line from full data refinement; second line from multipole refinement.

\begin{tabular}{|c|c|c|c|c|}
\hline Atom & $x$ & $y$ & $z$ & $B_{\text {eq }}$ \\
\hline \multirow[t]{2}{*}{$\mathrm{Co}$} & 0.5000 & 0.0000 & 0.0000 & $0.87(4)$ \\
\hline & 0.5000 & 0.0000 & 0.0000 & $0.83(8)$ \\
\hline \multirow[t]{2}{*}{ O5 } & $0.4921(6)$ & $0.0410(5)$ & $0.2069(7)$ & $1.52(2)$ \\
\hline & $0.4921(4)$ & $0.0411(7)$ & $0.2071(1)$ & $1.48(2)$ \\
\hline \multirow[t]{2}{*}{ N1 } & $0.6216(6)$ & $-0.0690(4)$ & $0.0469(7)$ & $1.04(2)$ \\
\hline & $0.6215(6)$ & $-0.0692(4)$ & $0.0469(8)$ & $1.02(2)$ \\
\hline \multirow[t]{2}{*}{$\mathrm{N} 2$} & $0.3739(6)$ & $-0.0678(4)$ & $0.0416(7)$ & $1.04(2)$ \\
\hline & $0.3739(6)$ & $-0.0680(4)$ & $0.0416(8)$ & $1.02(2)$ \\
\hline \multirow[t]{2}{*}{ N3 } & $0.3917(7)$ & $-0.1393(5)$ & $0.1018(8)$ & $1.27(2)$ \\
\hline & $0.3915(7)$ & $-0.1393(5)$ & $0.1016(9)$ & $1.25(2)$ \\
\hline \multirow[t]{2}{*}{ N4 } & $0.5993(7)$ & $-0.1394(5)$ & $0.1070(8)$ & $1.28(2)$ \\
\hline & $0.5996(7)$ & $-0.1394(5)$ & $0.1069(8)$ & $1.26(2)$ \\
\hline \multirow[t]{2}{*}{$\mathrm{C} 5$} & $0.4965(8)$ & $-0.1783(5)$ & $0.0582(9)$ & $1.30(2)$ \\
\hline & $0.4966(6)$ & $-0.1784(5)$ & $0.0584(9)$ & $1.28(2)$ \\
\hline \multirow[t]{2}{*}{ C6 } & $0.2724(7)$ & $-0.0370(5)$ & $0.0278(8)$ & $1.15(2)$ \\
\hline & $0.2723(6)$ & $-0.0370(5)$ & $0.0276(8)$ & $1.11(2)$ \\
\hline \multirow[t]{2}{*}{$\mathrm{C} 7$} & $0.7251(7)$ & $-0.0418(5)$ & $0.0317(8)$ & $1.13(2)$ \\
\hline & $0.7251(6)$ & $-0.0418(5)$ & $0.0319(8)$ & $1.11(2)$ \\
\hline \multirow[t]{2}{*}{$\mathrm{C} 8$} & $0.8311(8)$ & $-0.0847(7)$ & $0.0710(1)$ & $1.76(3)$ \\
\hline & $0.8313(8)$ & $-0.0846(6)$ & $0.0706(1)$ & $1.71(3)$ \\
\hline \multirow[t]{2}{*}{ C9 } & $0.1625(8)$ & $-0.0742(7)$ & $0.0701(1)$ & $1.63(3)$ \\
\hline & $0.1624(7)$ & $-0.0743(6)$ & $0.0697(1)$ & $1.60(3)$ \\
\hline \multirow[t]{2}{*}{$\mathrm{CL}$} & $0.7339(2)$ & $0.1789(1)$ & $0.2462(2)$ & $1.25(6)$ \\
\hline & $0.7339(1)$ & $0.1788(1)$ & $0.2461(2)$ & $1.20(6)$ \\
\hline \multirow[t]{2}{*}{$\mathrm{O} 1$} & $0.7636(9)$ & $0.2124(5)$ & $0.1252(8)$ & $2.55(3)$ \\
\hline & $0.7634(1)$ & $0.2124(8)$ & $0.1246(1)$ & $2.47(4)$ \\
\hline \multirow[t]{2}{*}{$\mathrm{O} 2$} & $0.7653(7)$ & $0.0961(4)$ & $0.2476(8)$ & $1.98(3)$ \\
\hline & $0.7651(1)$ & $0.0958(5)$ & $0.2476(1)$ & $1.93(3)$ \\
\hline \multirow[t]{2}{*}{$\mathrm{O} 3$} & $0.7905(7)$ & $0.2205(5)$ & $0.3469(8)$ & $2.38(3)$ \\
\hline & $0.7904(1)$ & $0.2206(8)$ & $0.3476(1)$ & $2.31(4)$ \\
\hline \multirow[t]{2}{*}{$\mathrm{O} 4$} & $0.6111(7)$ & $0.1840(5)$ & $0.2632(1)$ & $2.62(3)$ \\
\hline & $0.6106(9)$ & $0.1838(7)$ & $0.2634(1)$ & $2.56(4)$ \\
\hline
\end{tabular}


Table 3. Selected bond lengths $[\AA]$ and angles $\left[^{\circ}\right]$ with esds in parentheses: spherical model in normal typeface, multipole model in italics.

\begin{tabular}{|c|c|c|}
\hline Bond (angle) & $125 \mathrm{~K}$ & $298 \mathrm{~K}$ \\
\hline \multicolumn{3}{|l|}{ cation } \\
\hline \multirow[t]{2}{*}{$\mathrm{Co}-\mathrm{N} 1$} & $1.9026(7)$ & $1.902(3)$ \\
\hline & $1.9041(2)$ & \\
\hline \multirow[t]{2}{*}{$\mathrm{Co}-\mathrm{N} 2$} & $1.9153(7)$ & \\
\hline & $1.9169(2)$ & \\
\hline \multirow[t]{2}{*}{$\mathrm{Co}-\mathrm{O} 5$} & $2.2854(9)$ & $2.302(4)$ \\
\hline & $2.2876(4)$ & \\
\hline \multirow[t]{2}{*}{$\mathrm{N} 1-\mathrm{N} 4$} & $1.374(1)$ & $1.390(4)$ \\
\hline & $1.370(1)$ & \\
\hline \multirow[t]{2}{*}{$\mathrm{N} 2-\mathrm{N} 3$} & $1.383(1)$ & \\
\hline & $1.378(1)$ & \\
\hline \multirow[t]{2}{*}{$\mathrm{N} 1-\mathrm{C} 7$} & $1.301(1)$ & $1.288(5)$ \\
\hline & $1.303(1)$ & \\
\hline \multirow[t]{2}{*}{$\mathrm{N} 2-\mathrm{C} 6$} & $1.301(1)$ & \\
\hline & $1.303(1)$ & \\
\hline \multirow[t]{2}{*}{ N4-C5 } & $1.462(1)$ & $1.453(5)$ \\
\hline & $1.462(1)$ & \\
\hline \multirow[t]{2}{*}{ N3-C5 } & $1.459(1)$ & \\
\hline & $1.464(1)$ & \\
\hline \multirow[t]{2}{*}{$\mathrm{C} 6-\mathrm{C} 7$} & $1.475(1)$ & $1.477(7)$ \\
\hline & $1.476(1)$ & \\
\hline \multicolumn{3}{|l|}{$\mathrm{ClO}_{4}^{-}$} \\
\hline \multirow[t]{2}{*}{$\mathrm{Cl}-\mathrm{O} 1$} & $1.437(1)$ & \\
\hline & $1.438(1)$ & \\
\hline \multirow[t]{2}{*}{$\mathrm{Cl}-\mathrm{O} 2$} & $1.447(1)$ & $1.508(8)$ \\
\hline & $1.453(1)$ & \\
\hline \multirow[t]{2}{*}{$\mathrm{Cl}-\mathrm{O} 3$} & $1.438(1)$ & $1.398(5)$ \\
\hline & $1.438(1)$ & \\
\hline \multirow[t]{2}{*}{$\mathrm{Cl}-\mathrm{O} 4$} & $1.445(1)$ & $1.334(4)$ \\
\hline & $1.452(1)$ & \\
\hline \multicolumn{3}{|l|}{ hydrogen bond } \\
\hline \multirow{2}{*}{$\mathrm{O} 4-\mathrm{H}(\mathrm{O} 5 \mathrm{a})$} & $2.07(3)$ & $2.166(1)$ \\
\hline & $1.876(1)$ & \\
\hline \multirow[t]{2}{*}{$\mathrm{O} 2-\mathrm{H}(\mathrm{O} 5 \mathrm{~b})$} & $2.13(4)$ & $2.149(8)$ \\
\hline & $1.852(1)$ & \\
\hline \multirow{2}{*}{$\mathrm{O} 2 \cdots \mathrm{O} 5$} & $2.842(1)$ & $2.890(9)$ \\
\hline & $2.841(1)$ & \\
\hline \multirow[t]{2}{*}{$\mathrm{O} 4 \cdots \mathrm{O} 5$} & $2.854(1)$ & $3.250(5)$ \\
\hline & $2.843(1)$ & \\
\hline \multicolumn{3}{|l|}{ cation } \\
\hline \multirow[t]{2}{*}{ N1-Co-N2 } & $98.29(3)$ & $98.7(1)$ \\
\hline & $98.12(1)$ & \\
\hline N2-Co-O5 & $86.24(3)$ & 90 \\
\hline & $86.25(1)$ & \\
\hline N1-Co-N2A & $81.73(3)$ & $81.3(1)$ \\
\hline & $81.88(1)$ & \\
\hline N1-Co-O5 & $88.28(3)$ & 90 \\
\hline & $88.40(1)$ & \\
\hline
\end{tabular}

are at the axial positions. The Co atom is located with $\overline{1}$ site symmetry in the same plane of four imino nitrogen atoms. $\mathrm{Co}-\mathrm{N}$ distances are 1.9026(7) $\AA(\mathrm{Co}-\mathrm{N} 1)$ and $1.9153(7) \AA$ $(\mathrm{Co}-\mathrm{N} 2)$, which are in the same range as related compounds $(1.897-1.915 \AA) .^{[1,2,4]}$ The $\mathrm{Co}-\mathrm{O} 5$ bond length at $125 \mathrm{~K}$ is 2.2854(8) $\AA$, which is significantly shorter than the one (2.302(4) A) at $298 \mathrm{~K}$. Contrary to the case at room temperature, the oxygen atom of the axial ligand is not exactly at the vertical position but is displaced by about $4^{\circ}$ from the normal of the plane. This significant difference found between the low-temperature and the room-temperature structures is believed to be the cause for the space group change from Cmca (298 K) to Pbca (125 K). The tilt of the water molecule is a consequence of the hydrogen bond between the water molecule and the perchlorate anion. The close proximity of $\mathrm{O}_{\mathrm{ClO}_{4^{-}}} \cdots \mathrm{O}_{\text {water }}(2.842(1)$ and 2.854(1) $\AA$ ) along the $a$ axis at $125 \mathrm{~K}$, are significantly shorter than those at $298 \mathrm{~K}(2.890(9)$ and $3.250(5) \AA)$. The crystal structure at $125 \mathrm{~K}$ can be described as a polymeric chain along the $a$ axis through hydrogen bonds between cations and anions, shown in Figure 2, whereas at $298 \mathrm{~K}$, one of these hydrogen bonds is missing because of the disorder of the $\mathrm{ClO}_{4}{ }^{-}$ion. The $\mathrm{N}-\mathrm{N}$ bond lengths are 1.374(1) and 1.383(1) $\AA$ for N1-N4 and $\mathrm{N} 2-\mathrm{N} 3$, respectively, which are slightly shorter than those at $298 \mathrm{~K}$; this may be regarded as caused by slight improvement of the delocalization of the macrocyclic ring at $125 \mathrm{~K}$. The $\mathrm{C} 5$, $\mathrm{N} 1, \mathrm{~N} 2, \mathrm{~N} 3, \mathrm{~N} 4$, and Co atoms make a chairlike six-membered ring.

Deformation density: The agreement indices of multipole refinements based on two symmetries $C_{\mathrm{i}}$ and $C_{2 \mathrm{~h}}$ are compared in Table 4. The internal coordinates applied in the multipole model are indicated in Figure 1b. Significant improvements on the agreement indices based on the additional multipole terms are apparent. Since there is no significant difference between the two models, the subsequent analyses will be based on the $C_{2 \mathrm{~h}}$ model. The aspherical electron distribution of an atom owing to bonding can be illustrated by experimental static deformation density maps $\left(\Delta \rho_{\mathrm{M}-\mathrm{A}}\right)$ and theoretical deformation maps $\left(\Delta \rho_{\mathrm{UHF}}, \Delta \rho_{\mathrm{DFT}}\right)$. Deformation density maps and a residual map, $\Delta \rho_{\text {residual }}$, of the molecular plane $(x y)$ containing the $\alpha$-diimine moiety and the octaaza moiety are shown in Figure 3. It is apparent that large positive deformation densities are found at the midpoint of $\mathrm{C}=\mathrm{N}$ and $\mathrm{C}-\mathrm{C}$ bonds. A good agreement between experiment and theory (both UHF and DFT) is depicted in Figure 3a, $3 \mathrm{c}$, and $3 \mathrm{~d}$. The residual density map, $\Delta \rho_{\text {residual }}$ (Figure $3 \mathrm{~b}$ ), is essentially featureless except near the Co ion. There is positive deformation density at each $\mathrm{N}$ atom pointing toward the Co center, an observation that strongly substantiates the $\sigma$-donor character of the imino-N ligand. The lone-pair electron density of the oxygen atoms also indicates a $\sigma$-donor character towards the electron depletion position of the Co nucleus, though lower density depletion around the Co nucleus is found in the $z$ direction than in the $x y$ direction (Supporting Information). An asymmetric appearance was often observed around the Co nucleus in experiments ${ }^{[11 b, 12]}$ in

Table 4. Agreement indices of two multipole refinements, (1) $C_{\mathrm{i}}$ symmetry, (2) $C_{2 \mathrm{~h}}$ symmetry.

\begin{tabular}{llllllll}
\hline & & $\mathrm{NP}^{[\mathrm{b}]}$ & $R_{1}{ }^{[\mathrm{c}]}$ & $R_{1 \mathrm{w}}{ }^{[\mathrm{d}]}$ & $R_{2}^{[\mathrm{e}]}$ & $R_{2 \mathrm{w}}^{[\mathrm{f}]}$ & $S^{[\mathrm{g}]}$ \\
\hline conventional & & 191 & 0.0330 & 0.0369 & 0.0355 & 0.0416 & 2.40 \\
monopole & $(1)$ & 176 & 0.0330 & 0.0360 & 0.0473 & 0.0555 & 2.34 \\
& $(2)$ & 165 & 0.0437 & 0.0369 & 0.0495 & 0.0559 & 2.23 \\
octapole & $(1)$ & 442 & 0.0271 & 0.0258 & 0.0326 & 0.0346 & 1.72 \\
& $(2)$ & 307 & 0.0288 & 0.0284 & 0.0360 & 0.0403 & 1.86 \\
hexadecapole $^{[\mathrm{a}]}$ & $(1)$ & 460 & 0.0264 & 0.0248 & 0.0320 & 0.0341 & 1.66 \\
& $(2)$ & 331 & 0.0284 & 0.0278 & 0.0357 & 0.0401 & 1.82 \\
\hline
\end{tabular}

[a] Only $\mathrm{Co}$ and $\mathrm{Cl}$ atoms up to hexadecapole. [b] $\mathrm{NP}=$ no. of parameters. [c] $R_{1}=\Sigma\left|F_{\mathrm{o}}-F_{\mathrm{c}}\right| / \Sigma\left|F_{\mathrm{o}}\right| . \quad[\mathrm{d}] R_{1 \mathrm{w}}=\left(\Sigma w\left|F_{\mathrm{o}}-F_{\mathrm{c}}\right|^{2 / \Sigma} w\left|F_{\mathrm{o}}\right|^{2}\right)^{1 / 2}$. [e] $R_{2}=\Sigma \mid F_{\mathrm{o}}^{2}-$ $\left.F_{\mathrm{c}}^{2}|/ \Sigma| F_{\mathrm{o}}\right|^{2}$. [f] $R_{2 \mathrm{w}}=\left(\Sigma w\left|F_{\mathrm{o}}^{2}-F_{\mathrm{c}}^{2}\right|^{2} / \Sigma w\left|F_{\mathrm{o}}\right|^{4}\right)^{1 / 2}$. [g] $S=\left[\Sigma w\left|F_{\mathrm{o}}^{2}-F_{\mathrm{c}}^{2}\right|^{2} /(\mathrm{NO}-\right.$ $\mathrm{NP})]^{1 / 2}(\mathrm{NO}=$ number of reflections $)$. 


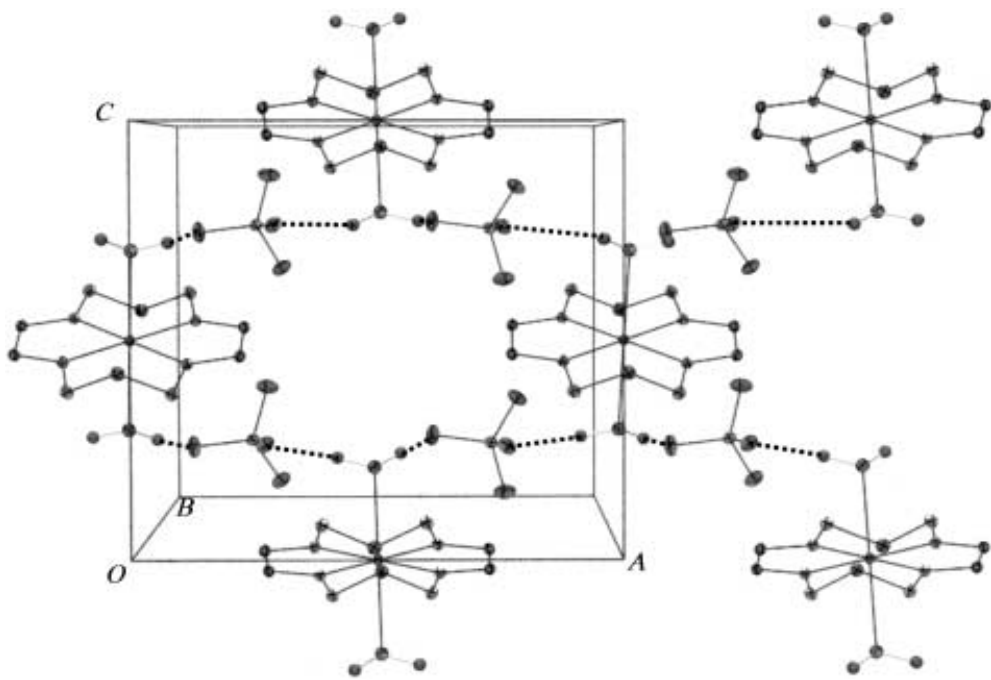

Figure 2. Packing diagram $(a=0-3 / 2, b=0-1 / 2, c=0-1)$ : for clarity, methyl groups and $\mathrm{H}$ atoms of the cation are neglected; the dashed line indicates the hydrogen bond between coordinated water molecules and perchlorate anions.

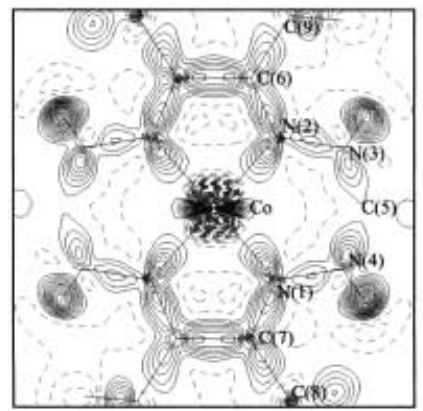

a)

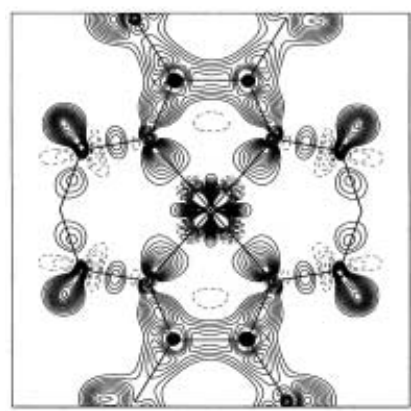

c)

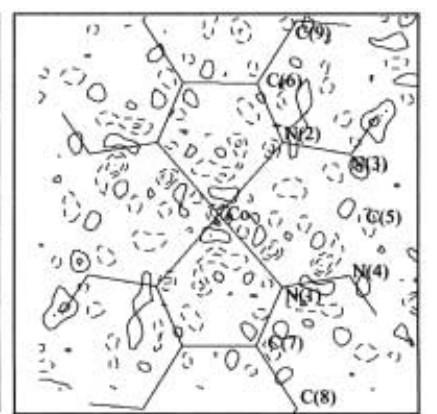

b)

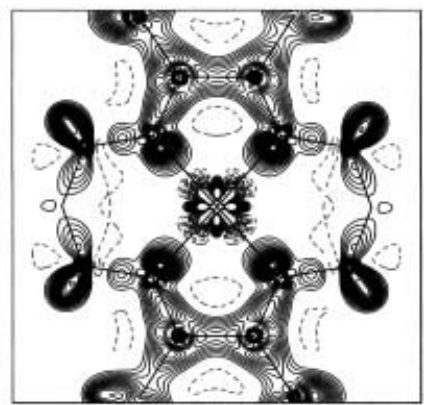

d)
Figure 3. Deformation density distribution, $\Delta \rho$, in the molecular plane $(x y)$; solid line positive, dotted line negative, contour interval $0.1 \mathrm{e} \AA^{-3}$, up to \pm 2 e $\AA^{-3}$ : a) $\Delta \rho_{\mathrm{M}-\mathrm{A}}$ from experiment; b) $\Delta \rho_{\text {residual }}$; c) $\Delta \rho_{\mathrm{M}-\mathrm{A}}$ from UHF; d) $\Delta \rho_{\mathrm{M}-\mathrm{A}}$ from DFT.

coordination spheres with a significant difference in the bite angles, for example $98^{\circ}$ versus $82^{\circ}(\Varangle \mathrm{N}-\mathrm{Co}-\mathrm{N})$ in this case.

Laplacian of electron density: The local electron density accumulation and depletion, or the valence-shell charge concentration (VSCC), can be visualized by a Laplacian of the electron density, $\nabla^{2} \rho$. The Laplacian of the total electron density derived from experiment (multipole model) and from UHF and DFT/UB3LYP calculations in the equatorial $(x y)$ plane are displayed in Figure 4 The charge concentration (CC) of the covalent bond character of intraligand $\mathrm{C}-\mathrm{C}, \mathrm{C}-\mathrm{N}$, and $\mathrm{N}-\mathrm{N}$ bonds and the lone-pair regions of imino- $\mathrm{N}$ toward $\mathrm{Co}$ are clearly shown. The local electron density concentrations of imino-N and of water-O atoms are directed toward the metal center, demonstrating the $\sigma$-donor character of the ligand. Thus the metal-ligand bond can be recognized as that of a Lewis acid-base pair. There is no significant difference between the UHF and DFT calculation, so in the subsequent results we will only show the DFT calculation.

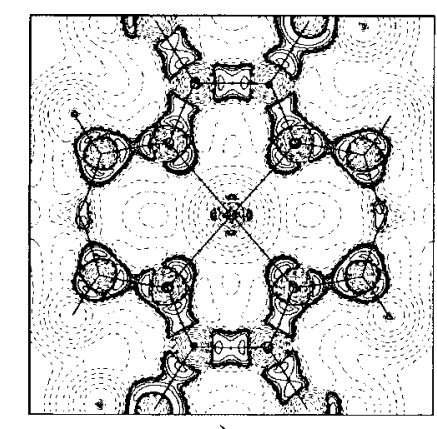

a)

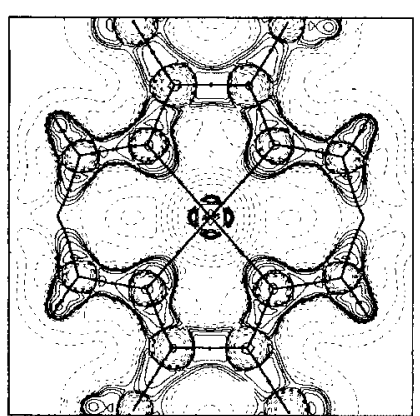

b)

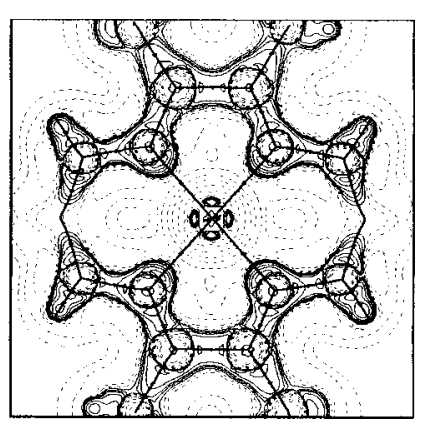

c)

Figure 4. Laplacian in the $x y$ plane derived from: a) experiment; b) UHF calculation; c) DFT calculation; solid line negative, dotted line positive, contours are $(-1)^{l} 2^{m} 10^{n}(l=1,0 ; m=1 \sim 3 ; n=-3 \sim 3)$ e $\AA^{-5}$. 
The asphericity in electron density distribution around the Co nucleus is an important piece of evidence for the understanding of the properties of metal-ligand bonding, which can also be recognized by the Laplacian of the electron density. The Laplacians for four unique planes around Co are shown in Figure 5. The CCs of the valence shell at the metal nucleus certainly appear at its third quantum shell. The local CC in $\mathrm{d}_{\pi}$ directions $\left(\mathrm{d}_{x z}, \mathrm{~d}_{y z}, \mathrm{~d}_{x^{2}-y^{2}}\right)$ and the local charge depletion in the $\mathrm{d}_{\sigma}$ direction $\left(\mathrm{d}_{x y}, \mathrm{~d}_{z^{2}}\right)$ are clearly shown on the map. For example, density depletion is visible in the $d_{\sigma}$ direction $\left(\mathrm{d}_{x y}\right.$ orbital) towards the nitrogen atoms, but density accumulation is found in the $\mathrm{d}_{\pi}\left(\mathrm{d}_{x^{2}-y^{2}}\right)$ direction (coordination is defined as in Figure 1b) in the horizontal plane. The agreement between experiment and theory is satisfactory. However, the separation between positive and negative Laplacian near the Co nucleus is much more pronounced in the experimental maps than in the theoretical maps. The other three planes also show large CCs in the $\mathrm{d}_{\pi}$ direction $\left(\mathrm{d}_{y z}, \mathrm{~d}_{x z}\right)$

a)

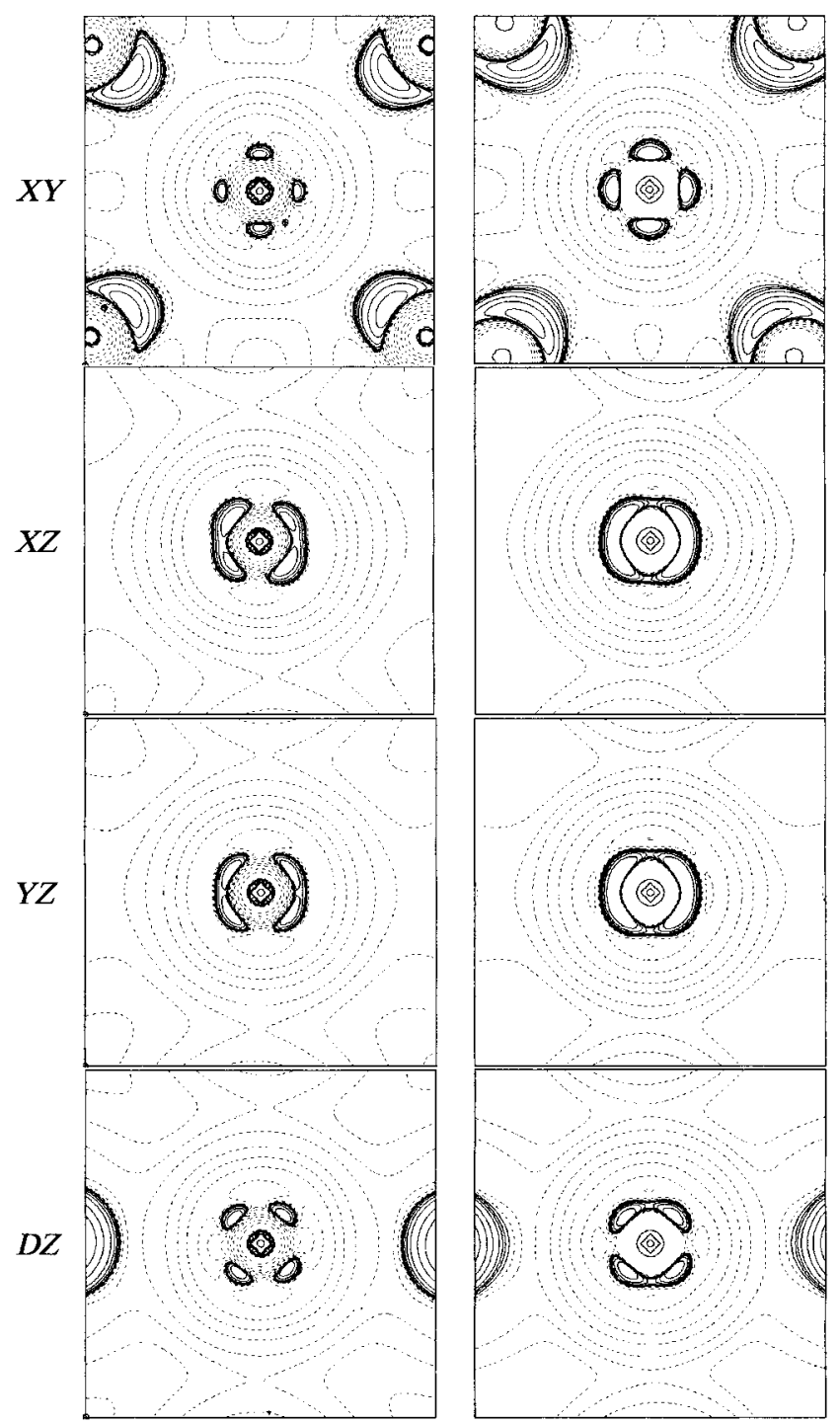

Figure 5. Laplacian of the Co atom in four different planes, defined on the left of the drawing; DZ is the plane perpendicular to the molecular plane and passing through N1-Co-N1': column a) from experiment; b) from DFT; contours are as in Figure 4. and charge depletion in the $d_{\sigma}$ direction $\left(d_{z^{2}}\right)$ both in experimental and in theoretical maps.

Atomic graph of Co and $\mathrm{Cl}$ atoms: In general, the bonded and nonbonded charge concentrations in the valence shell of a bonded atom, determined by the Laplacian of $\rho(r)$, are in good agreement with the corresponding properties that are ascribed to bonded and nonbonded pairs in Gillespie's VSEPR model of molecular geometry. ${ }^{[13]}$ An atomic $\operatorname{graph}^{[14,15]}$ is a polyhedron around the nucleus. Such a polyhedron is defined by the vertices, $V(\mathrm{CCs})$, the edges, $E$, and the faces, $F$, where the face critical point is a local maximum Laplacian value and represents a local depletion of the charge density. The polyhedron follows Euler's formula $V-E+F=2$.

A three-dimensional envelope plot of an isovalue Laplacian surface, $L(r)$, of the Co atom derived from experiment and from the DFT calculation is presented in Figure 6. The atomic

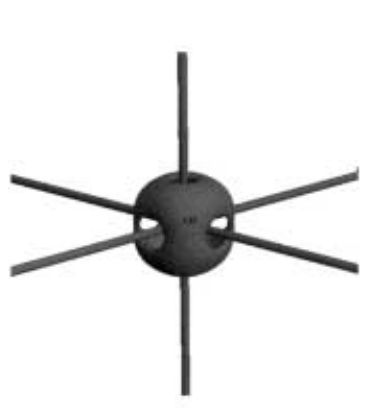

a)

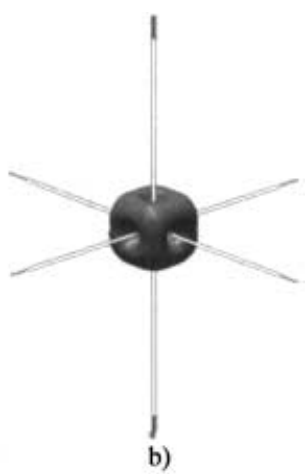

b)

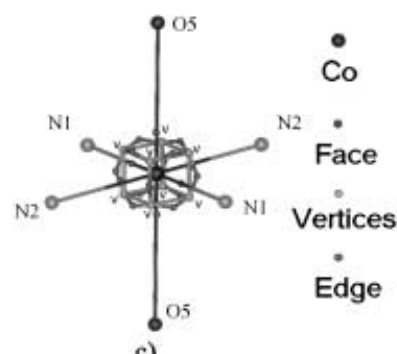

c)

Figure 6. Envelope map of isovalue surfaces of the Laplacian around Co a) from experiment; b) from DFT; c) schematic drawing for the atomic graph of Co: vertices are marked as $\mathrm{V}$; edges are linked between verticies; face CPs are along the $\mathrm{Co}-\mathrm{L}$ bonds.

graph shows eight vertices (CCs) in the VSCC of the Co nucleus, forming a cubelike polyhedron. This geometry can be explained as the linear combination of $\mathrm{d}_{x^{2}-y^{2}}, \mathrm{~d}_{x z}$, and $\mathrm{d}_{y z}$ orbitals of the cobalt atom. The polyhedron consists of eight vertices, six faces, and twelve edges, following Euler's formula. The vertices, edges centered at the bond critical point $(\mathrm{BCP})$, and the face critical point $(\mathrm{CP})$ around the Co center are plotted in Figure $6 \mathrm{c}$. The detailed descriptions of each polyhedron from experiment and from theoretical calculation agree well with each other (Supporting Information). Each $\mathrm{CC}$ of a coordinated ligand atom $(\mathrm{N}, \mathrm{O})$ caps one of the six faces $(F)$ of the approximately cubic polyhedron 
formed by the eight vertices, which are the CCs in the VSCC of the Co atom. The detailed geometry of the polyhedron of the atomic graph is comparable with those reported by Bader. ${ }^{[14]}$ Such an atomic graph was firstly described in the case of $\left[\mathrm{Cr}(\mathrm{CO})_{6}\right],{ }^{[15 \mathrm{~b}]}$ where the vertices are at the corners of a cube.

The perchlorate anion has a tetrahedral geometry. According to the VSEPR model, four bonded pairs should be formed around the $\mathrm{Cl}$ center. The Laplacian in the plane of O1-Cl-O2 is shown in Figure 7. It is clearly demonstrated that the local

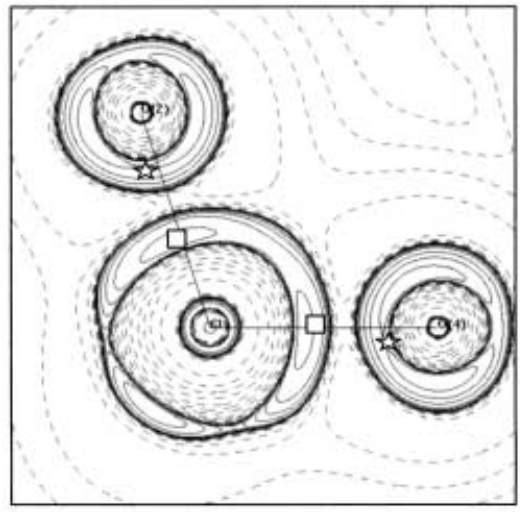

a)

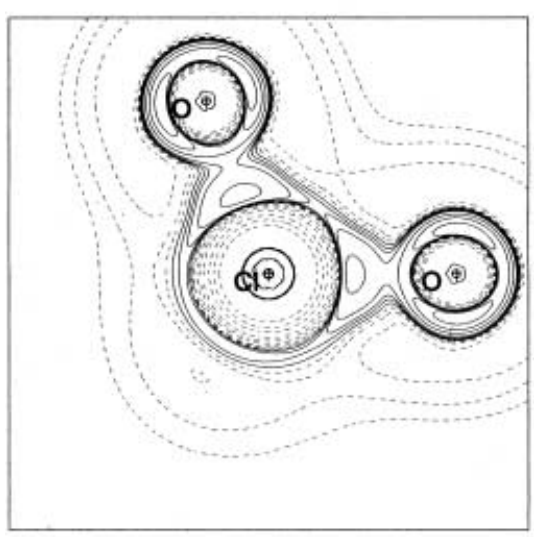

b)

Figure 7. Laplacian in one of the O-Cl-O planes; contours are as in Figure 4; $\square$ denotes the local Laplacian minimum, is denotes the local Laplacian maximum, a) from experiment; b) from DFT calculation.

CCs of the chlorine atom ( $\square$ ) are directed toward the local depletion ( $\succsim$ ) of the oxygen atoms, and $\mathrm{Cl}-\square-\succsim-\mathrm{O}$ is almost collinear. This indicates that the bond pair has donating character, from the $\mathrm{Cl}$ to the $\mathrm{O}$ atom.

The three-dimensional envelope plots of isovalue Laplacian surface, $L(r)$, and the atomic graph of the chlorine atom are shown in Figure 8 . There are four vertices $(V=4)$, six edges $(E=6)$, and four faces $(F=4)$ in the atomic graph of $\mathrm{Cl}$. Each $\mathrm{CC}$ is directed toward an oxygen atom. Apparently the bonding characteristics of $\mathrm{ClO}_{4}^{-}$are quite different from those in the corresponding Co complex cation. In the case of $\mathrm{ClO}_{4}^{-}$, the central $\mathrm{Cl}$ atom serves as an electron-pair donor, while in the case of $\left[\mathrm{Co}^{\mathrm{II}}\left(\mathrm{C}_{12} \mathrm{H}_{20} \mathrm{~N}_{8}\right)\left(\mathrm{H}_{2} \mathrm{O}\right)_{2}\right]$, the central Co atom serves as an electron-pair acceptor along the interatomic axis. The latter is encountered in coordination complexes,

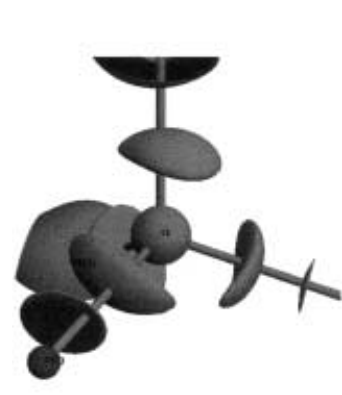

a)

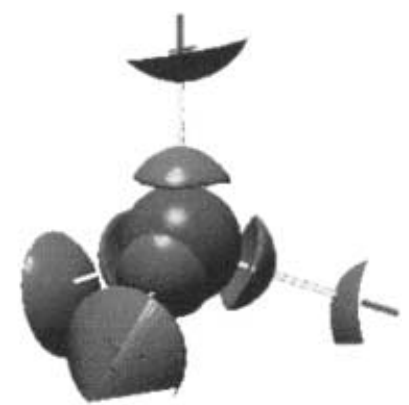

b)

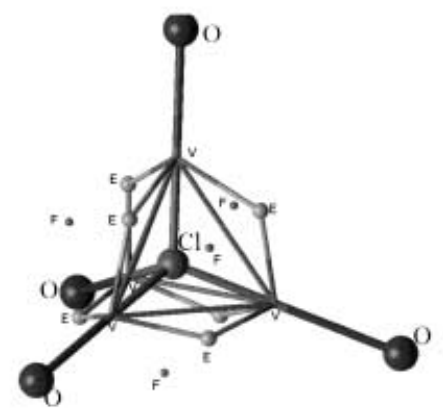

c)

Figure 8. Envelope map isovalue surface of Laplacian around $\mathrm{Cl}$ : a) from experiment; b) from DFT; c) schematic drawing for the atomic graph of $\mathrm{Cl}$. Vertices, edges, and face $\mathrm{CP}$ are marked in as $\mathrm{V}, \mathrm{E}$, and $\mathrm{F}$ respectively.

whereas the former is usually found in normal metal oxides or chlorides. ${ }^{[13 \mathrm{~d}]}$

Topological properties: The gradient vector fields of the electron density of the cation in the molecular plane derived from experiment and theoretical calculation are shown in Figure 9. The $\mathrm{CP}$ of atomic sites $(3,-3)$ and the ring $\mathrm{CP}(3$, $+1)$ in the five- and six-membered rings are quite observable from the termination of the trajectories. The atom domain can be recognized from this figure as well. The imino $\mathrm{N}$ atom and the connected $\mathrm{C}$ atom in this projection adopt a triangular shape indicating an $\mathrm{sp}^{2}$-type bonded atom. The Co atom in this plane shows a square planar shape. The $\mathrm{BCP}$ and bond paths are located at each chemical bond; for example, those in the $x y$ plane from experiment and theory are shown in Figure 10. Atom domains in this projection are also clearly shown in this figure. The agreement between experiment and theory is good. From the partition of the atom domain, the AIM integrated charge ${ }^{[14]}$ can be derived. Detailed topological properties associated with the BCP are listed in Table 5. According to the Laplacian at the $\mathrm{BCP}$, the $\mathrm{Co}^{-} \mathrm{N}$ and $\mathrm{Co}^{-} \mathrm{O}$ bonds are in closed-shell interactions (ionic character); however, the local energy density, $H_{\mathrm{b}}$, certainly indicates that there is covalent character, at least, in the $\mathrm{Co}^{-} \mathrm{N}$ bond. Further investigation by Fermi hole function (shown below) suggests there is certainly some covalent character in the $\mathrm{Co}^{-} \mathrm{N}$ bond but very little in $\mathrm{Co}^{-} \mathrm{O}$ bonds.

The density at the BCP, $\rho\left(r_{c}\right)$, of the $\mathrm{Co}^{-} \mathrm{O}$ bond is significantly lower than the densities of $\mathrm{M}-\mathrm{O}$ bonds $(0.2$ vs. $0.4 \mathrm{e}^{-3}$ ) of other complexes. ${ }^{[16]}$ This may be correlated with 


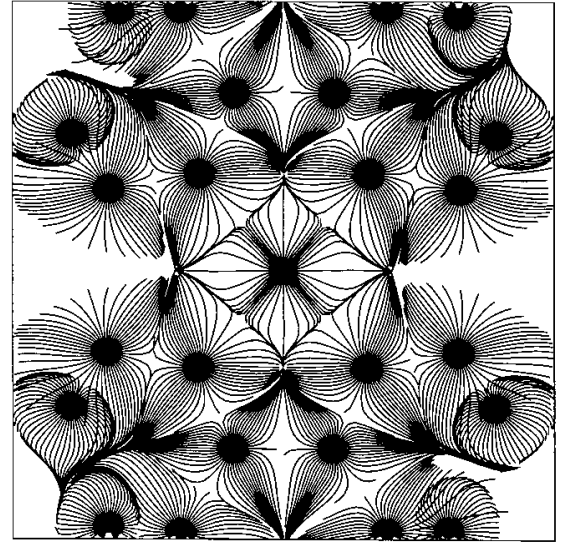

a)

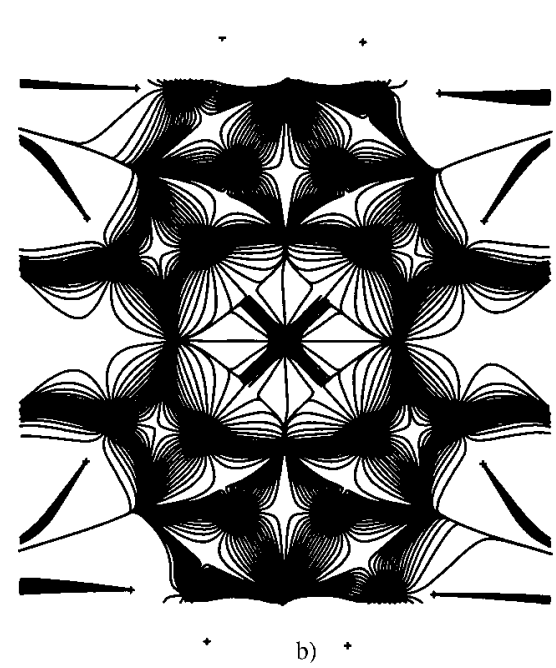

Figure 9. Gradient vector field in the $x y$ plane: a) from experiment; b) from DFT calculation.

the Jahn - Teller distortion of the $\mathrm{d}^{7}$ system, which results in the lengthening of the axial $\mathrm{M}-\mathrm{O}$ bond. All $\mathrm{C}-\mathrm{C}, \mathrm{C}-\mathrm{N}$, and $\mathrm{N}-\mathrm{N}$ bonds of the ligand, as well as the $\mathrm{Cl}-\mathrm{O}$ bond of the anion, show clear covalent character with $\nabla^{2} \rho\left(r_{\mathrm{c}}\right)<0$ and a value of 1.5-2.8 for $\rho\left(r_{\mathrm{c}}\right)$. More importantly, the large negative $H_{\mathrm{b}}$ values indicate the substantial stabilization of the local potential energy due to the shared interaction (covalent character). The $\mathrm{N}-\mathrm{N}$ and $\mathrm{N}-\mathrm{C} 7$ bonds appear to have higher $\rho\left(r_{\mathrm{c}}\right)$ values of $2.0-2.3$ than the other bonds (1.52.0). It may be fair to say that partial double-bond character is delocalized in these $\mathrm{N}-\mathrm{N}$ and $\mathrm{N}-\mathrm{C}$ bonds (as indicated in Scheme 1); this will be substantiated in the Fermi hole function analysis discussed in the following.

Hydrogen bond: There is a hydrogen-bond interaction between the oxygen atom of perchlorate and the coordinated water molecule. It can be substantiated by the topological analysis results. The density at the $\mathrm{BCP}, \rho\left(r_{\mathrm{c}}\right)$, is about $0.1 \mathrm{e} \AA^{-3}$, and the near-zero value of $H_{\mathrm{b}}$ (Table 5) is comparable to a medium hydrogen-bond interaction. ${ }^{[14,17]}$ The 3D topological envelope in the environment of the hydrogen bond between the $\mathrm{O} 4$ atom of $\mathrm{ClO}_{4}^{-}$and the $\mathrm{H} 5-\mathrm{O} 5$ of water molecule is depicted in Figure 11. A Laplacian vertex of $\mathrm{O} 4$ is

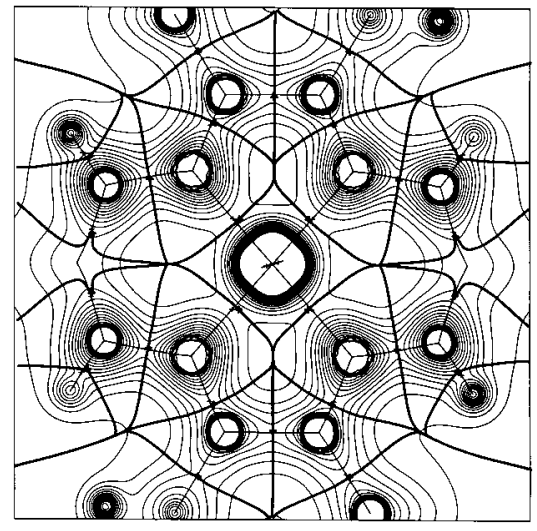

a)

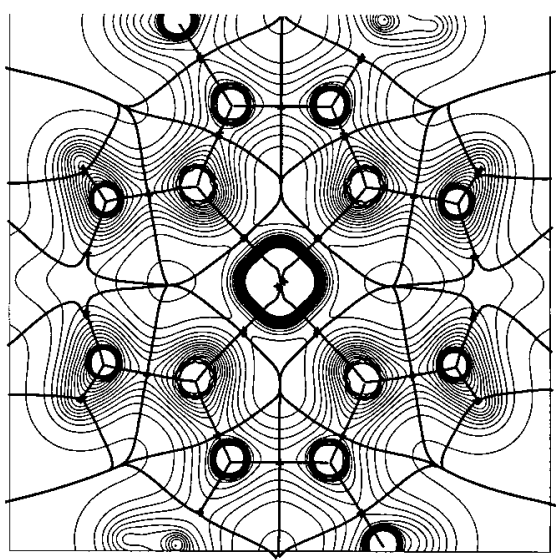

b)

Figure 10. Total electron density, bond path, and atom domain in the molecular plane: a) from experiment; b) from DFT calculation.

directed toward the secondary Laplacian charge depletion of $\mathrm{H} 5$, which is a Lewis acid-base pair binding interaction. ${ }^{[17]}$

Fermi hole function: It has been demonstrated ${ }^{[18]}$ that all physical measures of electron localization or delocalization can be determined by the corresponding localization or delocalization of the Fermi hole density. The Fermi hole density is depicted in Figure $12 \mathrm{a}-\mathrm{d}$ with the reference electron located at $0.35 \AA$ above the molecular plane at various atomic sites. The density spread in space indicates the existence of delocalization. However, the density spread in the space of the $\mathrm{p}_{\pi}$ direction is not a very extensive one, being limited to the atoms in the molecular plane, namely N4-N1$\mathrm{C} 7$, where the $\rho\left(r_{\mathrm{c}}\right)$ values are significantly higher than those of other bonds (Table 5).

In order to probe the $\mathrm{Co}^{-} \mathrm{N}$ and $\mathrm{Co}^{-} \mathrm{O} \sigma$-bond character, we have plotted a Fermi hole density in Figure $12 \mathrm{e}-\mathrm{f}$, with the reference electron located at the $\mathrm{CCs}$ of $\mathrm{O}$ and $\mathrm{N}$ atoms toward the Co atom. The Fermi hole density clearly indicates the covalent character along the $\mathrm{Co}-\mathrm{N} \sigma$-bond (Figure 12f). The $\mathrm{Co}-\mathrm{O}$ bond has nearly ionic character, with very little Fermi density distribution found near the Co center atom (Figure 12e); this fact is consistent with the difference in $\rho\left(r_{\mathrm{c}}\right)$ and $H_{\mathrm{b}}$ values of the $\mathrm{Co}-\mathrm{N}$ and $\mathrm{Co}-\mathrm{O}$ bond. The covalent character between $\mathrm{Co}$ and the four imino- $\mathrm{N}$ atoms can be easily recognized as the interaction between the $\mathrm{sp}^{2}$ hybrid 
Table 5. Properties of bond critical point: a) experimental; b) UHF; c) DFT.

\begin{tabular}{|c|c|c|c|c|c|c|}
\hline 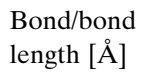 & & $d_{1}[\AA]$ & $\lambda_{3}\left[\mathrm{e} \AA^{-5}\right]$ & $\nabla^{2} \rho\left(r_{\mathrm{c}}\right)\left[\mathrm{e} \AA^{-5}\right]$ & $\rho\left(r_{\mathrm{c}}\right)\left[\mathrm{e} \AA^{-3}\right]$ & $H_{\mathrm{b}}\left[\mathrm{H} \AA^{-3}\right]$ \\
\hline \multicolumn{7}{|l|}{ cation } \\
\hline $\mathrm{Co}-\mathrm{N} 1$ & a & 0.926 & 19.85 & 11.98 & 0.783 & -0.255 \\
\hline \multirow[t]{2}{*}{$1.9026(7)$} & $\mathrm{b}$ & 0.883 & 22.04 & 18.17 & 0.588 & -0.052 \\
\hline & $\mathrm{c}$ & 0.874 & 22.10 & 17.49 & 0.507 & -0.078 \\
\hline $\mathrm{Co}-\mathrm{O} 5$ & $\mathrm{a}$ & 1.144 & 6.00 & 4.13 & 0.279 & 0.001 \\
\hline \multirow[t]{2}{*}{$2.2854(9)$} & $\mathrm{b}$ & 1.088 & 5.79 & 4.70 & 0.202 & -0.007 \\
\hline & $\mathrm{c}$ & 1.082 & 5.05 & 4.14 & 0.132 & -0.019 \\
\hline $\mathrm{N} 1-\mathrm{N} 4$ & $\mathrm{a}$ & 0.705 & 32.91 & -7.18 & 2.446 & -3.731 \\
\hline \multirow[t]{2}{*}{$1.374(1)$} & $\mathrm{b}$ & 0.713 & 17.58 & -19.56 & 2.140 & -3.308 \\
\hline & $\mathrm{c}$ & 0.719 & 22.08 & -18.01 & 2.174 & -3.348 \\
\hline $\mathrm{N} 1-\mathrm{C} 7$ & $\mathrm{a}$ & 0.837 & 11.84 & -29.04 & 2.503 & -4.381 \\
\hline \multirow{2}{*}{$1.301(1)$} & $\mathrm{b}$ & 0.876 & 32.85 & -0.61 & 2.030 & -2.626 \\
\hline & $\mathrm{c}$ & 0.868 & 24.95 & -10.93 & 2.178 & -3.192 \\
\hline $\mathrm{N} 4-\mathrm{C} 5$ & a & 0.875 & 12.90 & -10.81 & 1.720 & -2.234 \\
\hline \multirow[t]{2}{*}{$1.462(1)$} & $\mathrm{b}$ & 0.951 & 9.31 & -11.12 & 1.518 & -1.869 \\
\hline & $\mathrm{c}$ & 0.935 & 9.74 & -12.50 & 1.565 & -1.985 \\
\hline C6-C7A & a & 0.737 & 13.16 & -17.85 & 2.042 & -3.054 \\
\hline \multirow[t]{2}{*}{$1.475(1)$} & $\mathrm{b}$ & 0.737 & 5.01 & -17.50 & 1.551 & -2.076 \\
\hline & $\mathrm{c}$ & 0.735 & 7.39 & -19.33 & 1.638 & -2.277 \\
\hline C7-C8 & $\mathrm{a}$ & 0.878 & 11.09 & -7.65 & 1.589 & -1.915 \\
\hline \multirow[t]{2}{*}{$1.492(1)$} & $\mathrm{b}$ & 0.853 & 5.54 & -13.28 & 1.433 & -1.772 \\
\hline & $\mathrm{c}$ & 0.870 & 8.07 & -12.84 & 1.491 & -1.861 \\
\hline \multicolumn{7}{|l|}{ anion } \\
\hline $\mathrm{Cl}-\mathrm{O} 1$ & a & 0.731 & 29.66 & -10.28 & 2.809 & -4.728 \\
\hline \multirow[t]{2}{*}{$1.437(1)$} & $\mathrm{b}$ & 0.548 & 30.353 & -4.38 & 2.624 & -4.548 \\
\hline & $\mathrm{c}$ & 0.564 & 21.04 & -7.93 & 2.529 & -4.338 \\
\hline $\mathrm{Cl}-\mathrm{O} 2$ & $\mathrm{a}$ & 0.701 & 24.21 & -12.18 & 2.536 & -4.052 \\
\hline \multirow[t]{2}{*}{$1.447(1)$} & $\mathrm{b}$ & 0.556 & 23.80 & -10.06 & 2.590 & -4.525 \\
\hline & $\mathrm{c}$ & 0.576 & 14.93 & -13.47 & 2.491 & -4.246 \\
\hline \multicolumn{7}{|c|}{ hydrogen bond } \\
\hline O4-HO5A & a & 1.328 & 2.95 & 1.41 & 0.115 & 0.015 \\
\hline \multirow[t]{2}{*}{$2.07(3)$} & $\mathrm{b}$ & 1.253 & 3.85 & 2.14 & 0.179 & 0.004 \\
\hline & $\mathrm{c}$ & 1.232 & 3.82 & 1.92 & 0.196 & -0.005 \\
\hline $\begin{array}{l}\mathrm{O} 2-\mathrm{HO} 5 \mathrm{~B} \\
2.13(4)\end{array}$ & $\mathrm{a}$ & 1.258 & 3.82 & 2.02 & 0.102 & 0.025 \\
\hline
\end{tabular}

orbital of $\mathrm{N}$ and the $\mathrm{d}$ orbital of $\mathrm{Co}$ as found in $\mathrm{NBO}$ analysis, even though it is characterized as a nonbonding orbital both of imino-N and Co d-orbitals (Table 6). It is clear that the Fermi hole density does help to clarify the bond character of an $\mathrm{M}-\mathrm{L}$ bond.

Natural bond orbital analysis: The bond hybridization and the bond order of various chemical bonds can also be derived from NBO analysis based on DFT/UB3LYP calculations. The natural bond hybrid orbital, bond occupancies, and bond order are listed in Table 6. Selected bond orders are shown in Figure 1a. Here, the N1-C7 bond has double-bond character with a bond order of 1.83 . This bond is stronger than that in the free ligand, which is proved by the $\mathrm{C}-\mathrm{N}$ stretching frequency, $\tilde{v}_{\mathrm{C}-\mathrm{N}}$, being blue-shifted from that of the free ligand $\left(1575 \rightarrow 1597 \mathrm{~cm}^{-1}\right) \cdot{ }^{[2,6]} \mathrm{N}-\mathrm{N}$ and $\mathrm{C}-\mathrm{C}$ bonds are all single bonds; nevertheless, this represents only one of the possible resonance forms. $\mathrm{Co}-\mathrm{N}$ and $\mathrm{Co}-\mathrm{O}$ bonds are essentially dative, illustrated in Figure 1a by heavy arrows. The nonbonding electron density around Co is evidently in a low-spin $\mathrm{d}^{7}$ configuration with the unpaired electron in the $\mathrm{d}_{z^{2}}$ orbital, though no $\mathrm{CC}$ is found in the Laplacian in this direction.

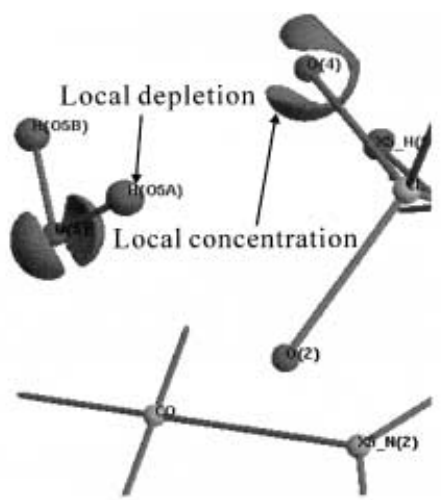

a)

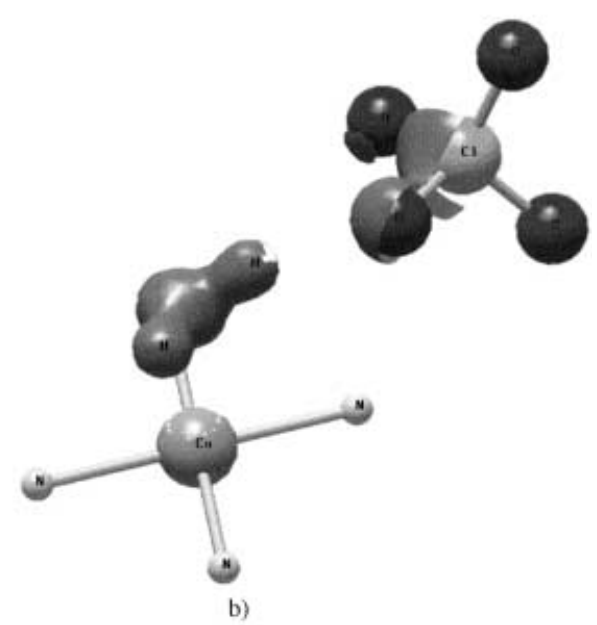

Figure 11. Three-dimensional Laplacian envelope of the O4 $\cdots \mathrm{H} 5$ hydrogen bond from: a) experiment; b) DFT calculation.

Net atomic charges and d orbital populations: Net atomic charges derived from multipole model and MO calculations are given in Table 7. Although the values differed somewhat between various analyses, the general trend is roughly the same. The coordinated atoms ( $\mathrm{N}$ and $\mathrm{O}$ ) of the octaaza ligand are all negatively charged, with the oxygen atom more negative than nitrogen atoms. This may indicate more polarized bond character in the $\mathrm{Co}-\mathrm{O}$ bond than in the $\mathrm{Co}-\mathrm{N}$ bond. The net atomic charge normally correlates strongly with the bonded atomic charge; the fragment charge is therefore compared. It is clearly indicated that the positive charge of the cation is dissipated among the atoms of the macrocyclic ligand. The water molecule is negatively charged on the basis of AIM charge; however it results as neutral from both monopole refinement and MO calculations. Since the MO calculations do not include the perchlorate anion, that is, the cation charge is fixed at $2+$, the comparison in values between experiment and theory is not exactly relevant.

The electron populations in the d orbitals can be derived from the multipole coefficients, $P_{\mathrm{lmp}}$, of the Co atom, which are listed in Table 8 . The d-orbital populations are presented in Table 9. The electronic configuration of cobalt is regarded as a low-spin $\mathrm{d}^{7}$ configuration both from the experimental and MO calculations, that is $\mathrm{d}_{x z}^{2}, \mathrm{~d}_{x^{2}-y^{2}}{ }^{2}, \mathrm{~d}_{y z}^{2}, \mathrm{~d}_{z^{2}}{ }^{1}$. It is evident that the $\mathrm{d}_{\sigma}$ orbitals $\left(\mathrm{d}_{x y}\right.$ and $\left.\mathrm{d}_{z^{2}}\right)$ are the most destabilized and the 


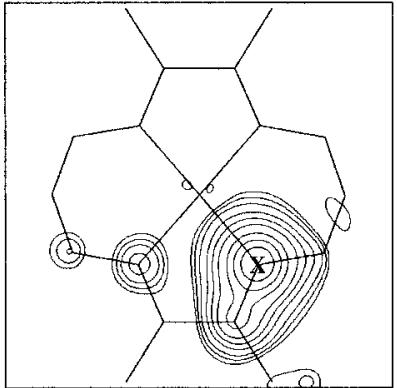

a)

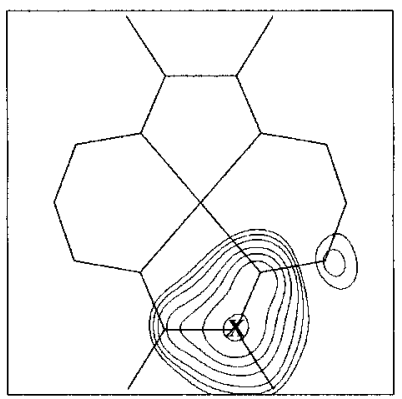

c)

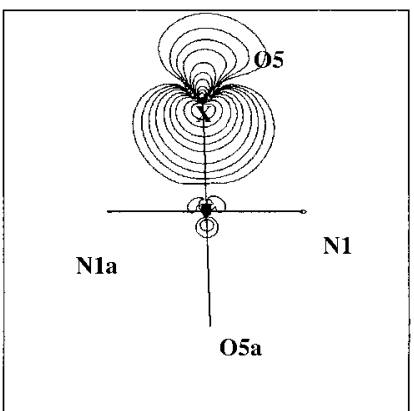

e)

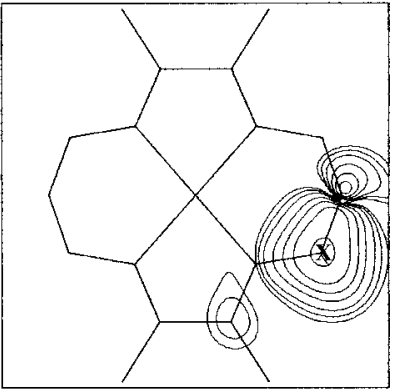

b)

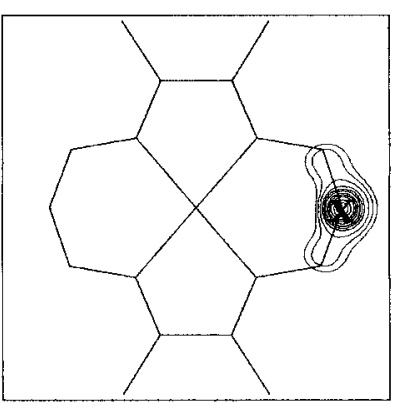

d)

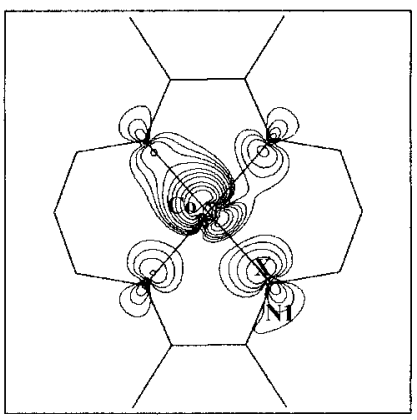

f)
Figure 12. Fermi hole (FH) distribution from DFT calculation: a) -d) in the plane $0.35 \AA$ above the molecular plane; the reference electron is indicated by $\mathbf{X}$ at a) N1; b) N4; c) C7; d) C5; e) and f) are the $\mathrm{FH}$ distribution in the molecular plane with the reference electron situated at the lone pair density maximum of e) $\mathrm{O} 5$; f) N1 toward the Co center.

least populated. The $\mathrm{d}_{x y}$ orbital (directed toward the nitrogen) is more so than the $\mathrm{d}_{z^{2}}$ orbital owing to Jahn - Teller distortion. The $\mathrm{d}_{\pi}$ orbitals $\left(\mathrm{d}_{x z}, \mathrm{~d}_{y z}, \mathrm{~d}_{x^{2}-y^{2}}\right)$ are all fully occupied. The singly occupied $\mathrm{d}_{z^{2}}$ orbital is clearly indicated in the MO calculation with $\alpha$-spin only (Table 9). Thus the $\mathrm{Co}^{\mathrm{II}}$ ion is in a low-spin $\mathrm{d}^{7}$ state and tetragonal bipyramidal coordination with the d-orbital energy levels of the order of $E\left(\mathrm{~d}_{x y}\right)>E\left(\mathrm{~d}_{z^{2}}\right)>$ $E\left(\mathrm{~d}_{x^{2}-y^{2}}\right) \cong E\left(\mathrm{~d}_{y z}, \mathrm{~d}_{x z}\right)$. This order of d-orbital energies is the same as found previously. ${ }^{[5 b]}$

\section{Conclusion}

The present study provides a detailed description of chemical bonding in $\left[\mathrm{Co}^{\mathrm{II}}\left(\mathrm{C}_{12} \mathrm{H}_{20} \mathrm{~N}_{8}\right)\left(\mathrm{H}_{2} \mathrm{O}\right)_{2}\right] \cdot 2 \mathrm{ClO}_{4}$ paramagnetic complex in terms of deformation density, Laplacian and topological analyses by $\mathrm{X}$-ray diffraction and quantum mechanical $\mathrm{MO}$ calculation. The $\mathrm{Co}^{\mathrm{II}}$ ion in tetragonal bipyramidal $\mathrm{N}_{4} \mathrm{O}_{2}$ coordination is in a $\mathrm{d}^{7}$ low-spin state with
Table 6. Natural bond hybrid orbital (NHO), bond order, and bond occupancies of various bonds from DFT calculations.

\begin{tabular}{|c|c|c|c|c|c|}
\hline Bond/bond type $\mathrm{e}^{[\mathrm{a}]}$ & Spin & Center & $\mathrm{NHO}$ & Occ. & Bond order \\
\hline $\mathrm{N} 1-\mathrm{N} 4$ & & & & & 0.98 \\
\hline \multirow[t]{2}{*}{$\sigma$} & $\alpha+\beta$ & $\mathrm{N} 1$ & $\mathrm{sp}_{\mathrm{x}}(54 \%)$ & 1.98 & \\
\hline & & N4 & $\mathrm{sp}_{\mathrm{x}}(46 \%)$ & & \\
\hline $\mathrm{N} 1-\mathrm{C} 7$ & & & & & 1.89 \\
\hline \multirow[t]{2}{*}{$\sigma$} & $\alpha+\beta$ & $\mathrm{N} 1$ & $\mathrm{sp}_{\mathrm{x}} \mathrm{p}_{\mathrm{y}}(61 \%)$ & 1.98 & \\
\hline & & $\mathrm{C} 7$ & $\mathrm{sp}_{\mathrm{x}} \mathrm{p}_{\mathrm{y}}(39 \%)$ & & \\
\hline \multirow[t]{2}{*}{$\pi$} & $\alpha+\beta$ & N1 & $\mathrm{p}_{z}(63 \%)$ & 1.96 & \\
\hline & & $\mathrm{C} 7$ & $\mathrm{p}_{z}(37 \%)$ & & \\
\hline $\mathrm{N} 4-\mathrm{C} 5$ & & & & & 0.98 \\
\hline \multirow[t]{2}{*}{$\sigma$} & $\alpha+\beta$ & $\mathrm{N} 1$ & $\mathrm{sp}_{\mathrm{y}} \mathrm{p}_{\mathrm{z}} \mathrm{p}_{\mathrm{x}}(61 \%)$ & 1.98 & \\
\hline & & N4 & $\mathrm{sp}_{\mathrm{y}} \mathrm{p}_{\mathrm{z}} \mathrm{p}_{\mathrm{x}}(38 \%)$ & & \\
\hline $\mathrm{C} 7-\mathrm{C} 8$ & & & & & 0.98 \\
\hline \multirow[t]{2}{*}{$\sigma$} & $\alpha+\beta$ & $\mathrm{N} 1$ & $\mathrm{sp}_{\mathrm{y}} \mathrm{p}_{\mathrm{x}}(55 \%)$ & 1.98 & \\
\hline & & $\mathrm{N} 4$ & $\mathrm{sp}_{\mathrm{y}} \mathrm{p}_{\mathrm{x}}(45 \%)$ & & \\
\hline C6-C7A & & & & & 0.98 \\
\hline \multirow[t]{2}{*}{$\sigma$} & $\alpha+\beta$ & C6 & $\mathrm{sp}_{\mathrm{x}}(50 \%)$ & 1.98 & \\
\hline & & C7A & $\mathrm{sp}_{\mathrm{x}}(50 \%)$ & & \\
\hline $\mathrm{n}$ & $\alpha$ & Co & $\mathrm{d}_{z^{2}}$ & 0.99 & \\
\hline $\mathrm{n}$ & $\alpha+\beta$ & Co & $\mathrm{d}_{x z}$ & 1.98 & \\
\hline $\mathrm{n}$ & $\alpha+\beta$ & Co & $\mathrm{d}_{y z}$ & 1.98 & \\
\hline $\mathrm{n}$ & $\alpha+\beta$ & Co & $\mathrm{d}_{x^{2}-y^{2}}$ & 1.98 & \\
\hline $\mathrm{n}$ & $\alpha+\beta$ & $\mathrm{N} 3, \mathrm{~N} 4$ & $\mathrm{sp}_{\mathrm{y}} \mathrm{p}_{\mathrm{x}}$ & 1.98 & \\
\hline $\mathrm{n}$ & $\alpha+\beta$ & $\mathrm{N} 1, \mathrm{~N} 2$ & $\mathrm{sp}_{\mathrm{y}} \mathrm{p}_{\mathrm{x}}$ & 1.98 & \\
\hline $\mathrm{n}$ & $\alpha+\beta$ & O5 & $\mathrm{sp}_{\mathrm{z}}$ & 1.98 & \\
\hline $\mathrm{n}$ & $\alpha+\beta$ & O5 & $\mathrm{sp}_{\mathrm{z}} \mathrm{p}_{\mathrm{x}}$ & 1.98 & \\
\hline
\end{tabular}

[a] $\mathrm{n}=$ non-bonding.

Table 7. Net atomic and fragment charges.

\begin{tabular}{lcrcc}
\hline Atom & Experimental & \multicolumn{3}{c}{ Theoretical MO calculations } \\
& AIM & $Z-P_{\text {val }}$ UHF & DFT/UB3-LYP \\
& Charge & & NPA & NPA \\
\hline $\mathrm{Co}$ & 0.80 & 0.41 & 1.31 & 1.48 \\
$\mathrm{~N} 1, \mathrm{~N} 2$ & $-0.96,-0.95$ & -0.17 & $-0.35,-0.36$ & $-0.50,-0.51$ \\
$\mathrm{~N} 3, \mathrm{~N} 4$ & $-0.62,-0.79$ & -0.26 & $-0.41,-0.41$ & $-0.46,-0.45$ \\
$\mathrm{O} 5$ & -1.38 & -0.72 & -0.76 & -0.90 \\
$\mathrm{C} 5$ & 0.25 & -0.20 & 0.07 & 0.04 \\
$\mathrm{C} 6, \mathrm{C} 7$ & $0.45,0.44$ & -0.05 & $0.25,0.25$ & $0.34,0.34$ \\
$\mathrm{C} 8, \mathrm{C} 9$ & $0.44,0.40$ & -0.67 & $-0.55,-0.55$ & $-0.55,-0.58$ \\
$\mathrm{H}(\mathrm{N} 3), \mathrm{H}(\mathrm{N} 4)$ & $0.38,0.37$ & 0.25 & $0.32,0.32$ & $0.36,0.36$ \\
$\mathrm{H}(\mathrm{O} 5 \mathrm{a}), \mathrm{H}(\mathrm{O} 5 \mathrm{~b})$ & $0.37,0.34$ & 0.38 & $0.43,0.43$ & $0.46,0.46$ \\
$\mathrm{H}(\mathrm{C5a})$ & 0.11 & 0.20 & 0.25 & 0.28 \\
$\mathrm{H}(\mathrm{C} 5 \mathrm{~b})$ & 0.11 & 0.28 & 0.14 & 0.16 \\
$3 \mathrm{H}(\mathrm{Me}-\mathrm{C} 8)$ & 0.56 & 1.00 & 0.64 & 0.68 \\
$3 \mathrm{H}(\mathrm{Me}-\mathrm{C} 9)$ & 0.52 & 1.00 & 0.67 & 0.72 \\
$\mathrm{Cl}$ & 2.31 & 1.37 & - & - \\
$\mathrm{O} 1, \mathrm{O} 3$ & $-0.68,-0.66$ & -0.50 & - & - \\
$\mathrm{O} 2, \mathrm{O} 4$ & $-0.72,-0.69$ & -0.54 & - & - \\
fragment charges & & & & \\
$\mathrm{Co}$ & 0.80 & 0.41 & 1.31 & 1.48 \\
$\mathrm{C}_{10} \mathrm{H}_{20} \mathrm{~N}_{8}$ & 1.36 & 0.97 & 0.57 & 0.47 \\
$\mathrm{H}_{2} \mathrm{O}$ & -0.67 & 0.01 & 0.06 & 0.02 \\
$\mathrm{ClO}{ }_{4}$ & -0.43 & -0.702 & -1.0 & -1.0 \\
\hline & & & &
\end{tabular}

the singly occupied orbital being $\mathrm{d}_{z^{2}}$. The bonding between Co and $\mathrm{N}$ or $\mathrm{O}$ in the coordination sphere is essentially a dative bond but with some covalent bond character in $\mathrm{Co}-\mathrm{N}$ bond. The atomic graph of $\mathrm{Co}$ is a hexahedron with eight vertices of charge concentration and six faces of charge depletion. The eight-cornered shape of the CC can be viewed as the linear combination of three fully occupied $\mathrm{d}_{\pi}\left(\mathrm{d}_{x^{2}-y^{2}}, \mathrm{~d}_{y z}, \mathrm{~d}_{x z}\right)$ orbitals. Each of the ligands caps one of the six faces of this 
Table 8. Multipole population coefficients of the Co atom in $C_{\mathrm{i}}$ and $C_{2 \mathrm{~h}}$ molecular symmetry.

\begin{tabular}{lrrl}
\hline$P_{\text {lmp }}$ & \multicolumn{1}{c}{$C_{\mathrm{i}}$} & \multicolumn{1}{c}{$C_{2 \mathrm{~h}}{ }^{\text {[a] }}$} & Functions \\
\hline$P_{00}$ & 3.640 & 3.729 & 1 \\
$P_{20}$ & 0.142 & 0.123 & $2 z^{2}-x^{2}-y^{2}$ \\
$P_{21}$ & -0.030 & -0.011 & $x z$ \\
$P_{2-1}$ & 0.006 & 0.030 & $y z$ \\
$P_{22}$ & 0.132 & -0.151 & $x^{2}-y^{2}$ \\
$P_{2-2}$ & 0.013 & -0.008 & $x y$ \\
$P_{40}$ & -0.162 & -0.160 & $8 z^{4}-24 x^{2} z^{2}-24 y^{2} z^{2}+6 x^{2} y^{2}+3 x^{4}+3 y^{4}$ \\
$P_{41}$ & -0.031 & 0.001 & $4 x z^{3}-3 z x^{3}-3 z y^{2} x$ \\
$P_{4-1}$ & 0.006 & 0.032 & $4 y z^{3}-3 z y x^{2}-3 z y^{3}$ \\
$P_{42}$ & 0.034 & -0.010 & $\left(x^{2}-y^{2}\right)\left(6 z^{2}-x^{2}-y^{2}\right)$ \\
$P_{4-2}$ & 0.028 & 0.034 & $2 x y\left(6 z^{2}-x^{2}-y^{2}\right)$ \\
$P_{43}$ & -0.052 & 0.000 & $z\left(x^{3}-3 x y^{2}\right)$ \\
$P_{4-3}$ & -0.004 & -0.032 & $z\left(y^{3}-3 y x^{2}\right)$ \\
$P_{44}$ & 0.133 & 0.098 & $4 x^{3} y-4 x y^{3}$ \\
$P_{4-4}$ & 0.014 & -0.010 & $x^{4}-6 x^{2} y^{2}+y^{4}$ \\
\hline
\end{tabular}

[a] The Co site has $C_{\mathrm{i}}$ symmetry.

Table 9. Experimental and theoretical results for d-orbital populations of the $\mathrm{Co}$ atom. $(\mathrm{NPA}=$ natural orbital population analysis.)

\begin{tabular}{|c|c|c|c|c|c|c|c|}
\hline \multirow[t]{3}{*}{$\mathrm{d}$} & \multirow{3}{*}{$\begin{array}{l}\text { Exptl } \\
\text { total }\end{array}$} & \multicolumn{6}{|c|}{ Theoretical MO calculations } \\
\hline & & \multicolumn{3}{|c|}{$\begin{array}{c}\mathrm{UHF} /\left(6-31 \mathrm{G}^{*}\right) \\
\mathrm{NPA}\end{array}$} & \multicolumn{3}{|c|}{$\begin{array}{c}\text { DFT/6-31G*) } \\
\text { NPA }\end{array}$} \\
\hline & & total & & $\beta$ & total & & $\beta$ \\
\hline $\mathrm{d}_{x y}$ & $0.85(7)$ & 0.48 & 0.25 & 0.23 & 0.34 & 0.19 & 0.15 \\
\hline $\mathrm{d}_{z^{2}}$ & $1.30(7)$ & 1.07 & 0.99 & 0.08 & 1.05 & 0.99 & 0.06 \\
\hline $\mathrm{d}_{y z}$ & $2.2(1)$ & 1.98 & 0.99 & 0.99 & 2.00 & 1.00 & 1.00 \\
\hline $\mathrm{d}_{x^{2}-y^{2}}$ & $1.47(7)$ & 1.98 & 0.99 & 0.99 & 2.01 & 1.01 & 1.00 \\
\hline $\mathrm{d}_{x z}$ & $1.6(1)$ & 1.84 & 0.92 & 0.92 & 1.99 & 1.00 & 0.99 \\
\hline total & 7.45 & 7.35 & & & 7.39 & & \\
\hline
\end{tabular}

hexahedron. In contrast, the atomic graph of the $\mathrm{Cl}$ of the perchlorate ion is a tetrahedron with four CCs at the vertices, each pointing toward a charge depletion of an oxygen atom. The bonding of a coordinated dative bond and a normal covalent bond is thus clearly demonstrated.

\section{Experimental Section and Computational Details}

Crystal structure and refinement: The title compound was prepared by template condensation according to the literature; $;^{[1,2]}$ the mother liquor was slowly evaporated under nitrogen and large dark brown prismatic crystals were formed. The chosen crystals were then sealed in a capillary and reflection intensities were measured on a CAD4 diffractometer both at $298 \mathrm{~K}$ and at $125 \mathrm{~K}$. The space group at $298 \mathrm{~K}$ is Cmca, a total of 4107 reflections was measured within $2 \theta_{\max }=50^{\circ}$, yielding 2163 unique reflections, the structural analyses were processed using NRCVAX ${ }^{[19]}$ program based on 993 observed $[I>2 \sigma(I)]$ reflections. The C-centered systematic absences were checked thoroughly and only six out of 2051 such reflections are larger than $5 \sigma(I)$. However, at $125 \mathrm{~K}$, the space group is $\mathrm{Pbca}$ and the C-centered absences no longer exist. Three reference reflections were measured every hour; the variations in intensity are within $\pm 2 \%$. Intensity data were first measured up to $2 \theta=85^{\circ}$ for a unique set of reflections $(-h,-k,-l)$ to ensure the symmetry. Four additional equivalent reflections $( \pm h, \pm k,+l),(+h,+k, \pm l)$ were measured afterwards. These yielded a total of 40050 reflections, which gave 8517 unique reflections after averaging of the equivalents. An absorption correction was applied before the averaging according to ten measured faces. The correctness of the absorption correction was checked against the experimental psi curves for three reflections, the agreement between the measured relative intensities and the calculated transmission was reasonable. The interset agreement between the intensities of equivalent reflections is 0.029 after applying the absorption correction. Data were corrected for Lorentz and polarization effects. The structure factor, $F_{\mathrm{o}}$, is derived from the averaging intensity; the standard deviation, $\sigma\left(F_{\mathrm{o}}\right)$, is calculated from a geometric mean of all the $\sigma$ values of equivalents. Conventional full-matrix least-squares refinements were performed with all the positional and anisotropic thermal parameters. The $\mathrm{H}$ atoms were relocated along the $\mathrm{C}-\mathrm{H}$ vectors to give the $\mathrm{C}-\mathrm{H}$ bond length of $1.08 \AA^{[20,21]}$ for the purpose of the deformation density studies. The crystal data and other details of the experimental conditions and refinements are given in Table 10. CCDC-171337 and 171338 contain the supplementary

Table 10. Crystal structure data at $298 \mathrm{~K}$ and $125 \mathrm{~K}$.

\begin{tabular}{|c|c|c|}
\hline formula & $\begin{array}{l}\mathrm{Co}\left[\mathrm{C}_{10} \mathrm{~N}_{8} \mathrm{H}_{20}\right]\left(\mathrm{H}_{2} \mathrm{O}\right)_{2} \\
\cdot 2 \mathrm{ClO}_{4}\end{array}$ & $\begin{array}{l}\mathrm{Co}\left[\mathrm{C}_{10} \mathrm{~N}_{8} \mathrm{H}_{20}\right]\left(\mathrm{H}_{2} \mathrm{O}\right)_{2} \\
\cdot 2 \mathrm{ClO}_{4}\end{array}$ \\
\hline$M_{\mathrm{r}}$ & 546.19 & 546.19 \\
\hline system & orthorhombic & orthorhombic \\
\hline space group & Cmca & Pbca \\
\hline$a[\AA]$ & $11.646(4)$ & $11.655(2)$ \\
\hline$b[\AA]$ & $17.049(4)$ & $16.930(4)$ \\
\hline$c[\AA]$ & $10.706(3)$ & $10.508(2)$ \\
\hline$V\left[\AA^{3}\right]$ & $2125.7(1)$ & 2073.4(6) \\
\hline$Z$ & 4 & 4 \\
\hline$\rho_{\text {calcd }}\left[\mathrm{g} \mathrm{cm}^{-3}\right]$ & 1.707 & 1.749 \\
\hline$\lambda\left(\mathrm{Mo}_{\mathrm{K} \alpha}\right)[\AA]$ & 0.7107 & 0.7107 \\
\hline$F(000)$ & 1124 & 1124 \\
\hline $2 \theta$ range $\left[{ }^{\circ}\right]^{[a]}$ & $30.2-44.8$ & $78.7-84.1$ \\
\hline scan type & $\theta / 2 \theta$ & $\theta / 2 \theta$ \\
\hline scan width $\left[{ }^{\circ}\right]$ & $2(0.65+0.35 \tan \theta)$ & $2(0.70+0.35 \tan \theta)$ \\
\hline $2 \theta_{\max }\left[{ }^{\circ}\right]$ & 50.0 & 85.0 \\
\hline$\mu\left(\mathrm{Mo}_{\mathrm{K} \alpha}\right)\left[\mathrm{cm}^{-1}\right]$ & 11.21 & 11.49 \\
\hline crystal size $[\mathrm{mm}]$ & $0.35 \times 0.40 \times 0.50$ & $0.35 \times 0.40 \times 0.50$ \\
\hline$T[\mathrm{~K}]$ & 298 & 125 \\
\hline reflections measured & 1879 & 40050 \\
\hline unique reflections & 1864 & 8517 \\
\hline $\begin{array}{l}\text { reflections observed } \\
{[I>2 \sigma(I)]}\end{array}$ & 993 & 5547 \\
\hline$R_{1} / R_{1 W}$ & $0.045 / 0.047$ & $0.033 / 0.037$ \\
\hline$R_{\text {int }}{ }^{[\mathrm{b}]}$ & - & 0.029 \\
\hline$S$ & 1.35 & 2.40 \\
\hline$g($ ext. coeff. $) \times 10^{4}$ & $0.9(3)$ & $0.27(3)$ \\
\hline$(\Delta / \sigma) \max$ & 0.008 & 0.0009 \\
\hline$(\Delta \rho) \min / \max \left[\mathrm{e}^{3} \AA^{3}\right]$ & $-0.4 / 0.64$ & $-0.56 / 0.68$ \\
\hline minimization function & $\Sigma\left(w\left|F_{\mathrm{o}}-F_{\mathrm{c}}\right|^{2}\right)$ & $\Sigma\left(w\left|F_{\mathrm{o}}-F_{\mathrm{c}}\right|^{2}\right)$ \\
\hline weight & $1 /\left[\sigma^{2}\left(F_{\mathrm{o}}\right)\right]$ & $1 /\left[\sigma^{2}\left(F_{\mathrm{o}}\right)+6 \times 10^{-5} F_{\mathrm{o}}^{2}\right]$ \\
\hline
\end{tabular}

[a] 25 reflections used for cell determination. [b] $R_{\text {int }}=\Sigma(I-\bar{I}) / \Sigma I$.

crystallographic data for this paper. These data can be obtained free of charge via www.ccdc.cam.ac.uk/conts/retrieving.html (or from the Cambridge Crystallographic Data Centre, 12 Union Road, Cambridge CB21EZ, UK; fax: (+44)1223-336033; or deposit@ccdc.cam.uk).

Additional multipole refinements were performed with the XD program, ${ }^{[22]}$ in which the atomic density is described as the sum of a spherical and a nonspherical part. The spherical part consists of a core density $\left(\rho_{\text {core }}\right)$, a valence density $\left(\rho_{\text {val }}\right)$ with adjustable population $P_{\text {val }}$ and a radial contraction - expansion parameter $(\kappa)$. The nonspherical part of the atomic electron density can be expressed ${ }^{[23]}$ as a series of spherical harmonic terms $Y_{\operatorname{lmp}}$ with variable population coefficients, $P_{\operatorname{lmp}} . P_{\text {val }}, P_{\operatorname{lmp}}, \kappa^{\prime}$, and $\kappa$ are refined parameters in addition to the atomic positional and thermal parameters. The multipole refinement was made with a multipole expansion of the valence shell up to hexadecapoles for the $\mathrm{Co}$ and $\mathrm{Cl}$ atom, up to octapoles for the $\mathrm{C}, \mathrm{N}$, and $\mathrm{O}$ atoms, and up to quadrupoles for the $\mathrm{H}$ atom. The $\kappa^{\prime}$-unrestricted multipole model (UMM) ${ }^{[24]}$ was created. Atomic scattering factors of both core and valence electrons were taken from the International Tables for X-Ray Crystallography. ${ }^{[21]} \mathrm{A}[\mathrm{He}]$ core 
was used for $\mathrm{C}, \mathrm{N}, \mathrm{O}, \mathrm{a}[\mathrm{Ne}]$ core for $\mathrm{Cl}$, and a [Ca] core for $\mathrm{Co}$. The valence electron configurations for $\mathrm{Co}, \mathrm{Cl}, \mathrm{C}, \mathrm{N}$, and $\mathrm{O}$ are $\mathrm{d}^{7}, \mathrm{~s}^{2} \mathrm{p}^{5}, \mathrm{~s}^{2} \mathrm{p}^{2}, \mathrm{~s}^{2} \mathrm{p}^{3}$, and $\mathrm{s}^{2} \mathrm{p}^{4}$, respectively. Two choices of molecular symmetry, $C_{\mathrm{i}}$ and $C_{2 \mathrm{~h}}$, were tried on the cation in the least-squares procedure for the multipole coefficients, $P_{\text {lmp }}$. There are more variables in the $C_{\mathrm{i}}$ model than in the $C_{2 \mathrm{~h}}$ model; however, insignificant improvement was found in the agreement indices of the $C_{\mathrm{i}}$ model. Therefore the $C_{2 \mathrm{~h}}$ model was chosen to be the basis for discussion of the cation, but the Co coefficient is still in $C_{\mathrm{i}}$ symmetry in order to be properly compared with the MO calculations. The coefficients of all the multipole terms together with positional and anisotropic thermal parameters were obtained by a full-matrix least-squares refinement based on $F_{\mathrm{o}}^{2}$.

Basis functions and geometry: For the ab initio MO calculation, the basis set used for the Co atom was $(14,9,6) /[8,4,3]$ contractions: $(62111111 / 5112 /$ $411),{ }^{[25,26]}$ where the $(14 \mathrm{~s}, 9 \mathrm{p})$ primitive Gaussian functions are taken from Wachters ${ }^{[26]}$ and $(6 \mathrm{~d})$ functions are from Goddard. ${ }^{[25]}$ The basis sets used for $\mathrm{N}, \mathrm{O}, \mathrm{C}$ and $\mathrm{H}$ were $6-31 \mathrm{G}^{*}$. All computations are made only on the cation $(2+)$. Because of the odd number of electrons, the calculation was made at the UHF level. The density functional calculations (DFT) used were nonlocal spin density corrections to the local spin density approximation (LSDA) ${ }^{[27]}$ functional with the LSD exchange and the Vosko, Wilk, and Nusair correction function (VWN). The exchange functional was the Becke's three-parameter hybrid method ${ }^{[28]}$ which used the correction functional of Lee, Yang, and Parr (B3LYP). ${ }^{[29,30]}$ The molecular geometry was taken from the diffraction study at $125 \mathrm{~K}$. The internal coordinates of the Co atom were defined so that the $y$ axis was at the bisection of $\Varangle$ N1-CoN2A and the $x$ axis was at the bisection of $\Varangle$ N1-Co-N2 (Figure 1b).

Deformation electron density: The deformation density distribution based on the multipole model ${ }^{[23]}$ was obtained by subtracting the spherical part of the atomic electron density with $P_{\text {val }}$ set as a neutral atom and the $\kappa$ values reset to 1.0 from the total electron density. All computations were carried out with NRCVAX ${ }^{[19]}$ and $\mathrm{XD}^{[22]}$ programs.

The theoretical deformation density $\left(\Delta \rho_{\text {theo }}\right)$ is defined as the difference between the total molecular electron density and the promolecular electron density. The total molecular electron density was calculated either from UHF or from DFT calculated molecular wave functions. The promolecular electron density is the sum of the superposition of the spherical atomic density with atoms located at the same nuclear positions as in the molecular geometry. The spherical atomic density was calculated at the ROHF/GVB level. All computations were performed with the Gaussian $98^{[28]}$ program. The AIMPAC ${ }^{[31]}$ routine was used for the deformation density and topological analysis.

Natural bond orbital analysis: The natural bond orbital (NBO) analysis $^{[32-35]}$ comprises a sequence of transformations from the given basis sets to various localized MO sets. These procedures derive their names and inspirations from the natural orbitals of Löwdin, ${ }^{[36]}$ which are obtained from the diagonalization of the one-particle density matrix. The given basis functions were taken from DFT/UB3LYP calculation. The results after NBO analysis were generally in good agreement with Lewis structure concept and the Pauling - Slater-Coulson ${ }^{[37]}$ concept of bond hybridization and polarization. Net atomic charges, orbital populations, and bond orders were thus generated by means of NBO analysis. The charges and orbital populations obtained this way were designated as natural orbital population analysis (NPA), and were compared with the Mulliken population analysis (MPA).

Topological analysis: Topological analysis based on the theory of atoms in molecules (AIM) ${ }^{[14]}$ was applied both to the experimental electron density (multipole model ${ }^{[23]}$ ) and to the theoretically calculated electron density (UHF and DFT). The BCPs and bond paths (BPs) of electron density can be used to construct a molecular graph representing the interactive network connecting bonded atoms. ${ }^{[38]}$

The Laplacian topology of electron density depicts the local charge concentration when $\nabla^{2} \rho(r)<0$ and the local charge depletion when $\nabla^{2} \rho(r)>0$. This Laplacian topology provides the physical basis for the Lewis structure and VSEPR models. ${ }^{[13]}$ The electron density at the BCP, $\rho\left(r_{\mathrm{c}}\right)$, is related to the bond strength or the bond order. ${ }^{[39]}$

It was suggested ${ }^{[39 c]}$ that the total energy density value, $H_{\mathrm{b}}$ (which is the sum of the kinetic energy density $G_{\mathrm{b}}$ and the potential energy density $V_{\mathrm{b}}$ ), at the $\mathrm{BCP}$ could be interpreted as a sufficient condition for a covalent bond when the sign of $H_{\mathrm{b}}$ is negative. Such a value may be used as a qualitative measure for covalency of a bond. The experimental $H_{\mathrm{b}}$ value is estimated by a generalized approach of Abramov's expression. ${ }^{[40]}$

Furthermore, the topological properties of $\nabla^{2} \rho(r)$ can be used to understand the active chemical reactive site and to reveal simple 3D directional interaction in the molecular crystal. A correlation between these CPs of $\nabla^{2} \rho(r)$ in the valence shell and the location of the active site in the molecule has been established. ${ }^{[14,15,41]}$ In principle, a Lewis acid-base reaction occurs owing to the fact that a local maximum of the VSCC on the Lewis base aligns itself as far as possible with a local minimum of the VSCC on the Lewis acid.

On the basis of AIM theory, ${ }^{[14]}$ the gradient vector field of the charge density is represented through a display of the trajectories traced out by the vector $\nabla \rho$. Every trajectory must originate or terminate at a point where $\nabla \rho(r)$ vanishes, that is, at a critical point of $\rho(r)$; starting at a BCP, paths for which the electron density decreases most rapidly are developed in all directions normal to the bond. The set of such paths defines a zero-flux surface separating a pair of bonded atoms. A set of those surfaces (one per bond) will partition a molecule into unique atom domains ( $\Omega$ atomic basins) for which the hypervirial theorem is satisfied. Numerical integration of the electron density within such a basin, $\Omega$, yields the charge assigned to that given atom: $\mathrm{q}_{\Omega}=\Sigma_{\Omega} \rho(r) \mathrm{d} \tau$. This is called the AIM atomic charge. The AIM atomic charges are calculated by the TOPXD ${ }^{[42]}$ program from the experimental charge density.

The Fermi hole function ${ }^{[18]}$ is an effective tool with which to study the electron localization and delocalization of the system. Therefore it can be utilized to understand the covalency of the bond. Detailed definitions of all these topological properties are given elsewhere. ${ }^{[13-15,38-41]}$ In this study, maps of the Laplacian were made by the $\mathrm{XDPROP}^{[22]}$ program; the gradient vector field and bond path were obtained by means of $\mathrm{PROP}^{[43]}$ and AIMPAC ${ }^{[31]}$ programs.

\section{Acknowledgements}

Thanks are due to Dr. Y.S. You for the supply of single crystals. Thanks are also due to Prof. Coppens for making the TOPXD program available. The valuable discussion with Prof. T.-H. Tang is appreciated. The authors would like to thank the National Science Council of the Republic of China for financial support and to the National High-Performance Supercomputer Center for access to hardware and software.

[1] a) V. L. Goedken, S. M. Peng, Adv. Chem. Ser. 1976, 150, 379-393; b) G. C. Gordon, S. M. Peng, V. L. Goedken, Inorg. Chem. 1978, 17, 3578-3586.

[2] Y. S. You, Ph.D. thesis, National Taiwan University (Taipei, Taiwan), 1995.

[3] The Porphyrins, Vols. 1 -7 (Ed.: D. Dolphin), Academic Press, New York, 1978.

[4] Coordination Chemistry of Macrocyclic Compounds (Ed.: G. Melson), Plenum, New York, 1979.

[5] a) A. L. Crumbliss, F. Basolo, J. Am. Chem. Soc. 1970, 92, 55; b) E. I. Ochiai, J. Inorg. Nucl. Chem. 1973, 35, 1727.

[6] A. Ceulemans, R. Debuyst, F. Dejehet, G. S. D. King, M. Vanhecke, L. G. Vanquickenborne, Inorg. Chem. Acta 1992, 192, 95-105.

[7] A. Ceulemans, M. Dendooven, L. G. Vanquickenborne, Inorg. Chem. 1985, 24, 1159-1165.

[8] A. Ceulemans, B. Coninckx, M. Vanhecke, T. Zeegers-Huyskens, G. S. D. King, Inorg. Chem. Acta. 1992, 202, 101-109.

[9] A. Ceulemans, R. Debuyst, F. Dejehet, G. S. D. King, M. Vanhecke, L. G. Vanquickenborne, J. Phys. Chem. 1990, 94, 105-113.

[10] J. E. Huheey, Inorganic Chemistry Principles of Structure and Reactivity, 3rd ed., Harper \& Row, New York, 1983, pp. 396-404.

[11] a) K. J. Lin, Y. Wang, J. Phys. Chem. 1993, 97, 3176-3182; b) A. S. Biré, N. Q. Dao, A. Strich, C. Thieffry, M. Bénard, Inorg. Chem. 1990, $29,4908-4915$; c) W. H. E. Schwarz, K. Ruedenberg, L. Mensching, J. Am. Chem. Soc. 1989, 111, 6926-6933; d) P. Coppens, M. B. Hall, Electron Distribution and the Chemical Bond, Plenum, New York, 1982; e) K. L. Kunze, M. B. Hall, J. Am. Chem. Soc. 1987, 109, $7617-$ 7623. 
[12] a) R. Restori, D. Schwarzenbach, J. R. Schneider, Acta Crystallogr. Sect. B 1987, 43, 251-257; b) C. Lecomte, R. H. Blessing, P. Coppens, A. Tabard, J. Am. Chem. Soc. 1986, 108, 6942-6950; c) N. Li, P. Coppens, J. Landrum, Inorg. Chem. 1988, 27, 482-488.

[13] a) R. J. Gillespie, I. Hargittai, The VSEPR Model of Molecular Geometry, Allen and Bacon, Boston, 1991; b) R. F. W. Bader, R. J. Gillespie, P. J. MacDougall, J. Am. Chem. Soc. 1988, 110, 7329; c) R. J. Gillespie, E. A. Robinson, Angew. Chem. 1996, 108, 539; Angew. Chem. Int. Ed. Engl. 1996, 35, 495; d) R. F. W. Bader, R. J. Gillespie, F. Martín, Chem. Phys. Lett. 1998, 290, 488.

[14] R. F. W. Bader, Atoms in Molecules: A Quantum Theory, Clarendon, Oxford, 1990

[15] a) R. F. W. Bader, P. L. A. Popelier, C. Chang, J. Mol. Struct. (THEOCHEM) 1992, 255, 145; b) P. J. MacDougall, M. B. Hall, Trans. Am. Crystallogr. Assoc. 1990, 26, 105-123.

[16] C. R. Lee, C. C. Wang, K. C. Chen, G. H. Lee, Y. Wang, J. Phys. Chem. 1999, A103, 156

[17] a) M. T. Carroll, C. Chang, R. F. W. Bader, Mol. Phys. 1988, 63, 387; b) T.-H. Tang, W.-J. Hu, D.-Y. Yan, Y.-P. Cui, J. Mol. Struct. (THEOCHEM) 1990, 207, 319; c) D. M. Whitefield, T.-H. Tang, J. Am. Chem. Soc. 1993, 115, 9648; d) U. Koch, P. L. A. Popelier, J. Phys. Chem. 1995, 99, 9747; e) T.-H. Tang, Y.-P. Cui, Can. J. Chem. 1996, 74, 1162; f) P. L. A. Popelier, J. Phys. Chem. A 1998, 102, 1873.

[18] R. McWeeny, Rev. Mod. Phys. 1960, 32, 325.

[19] E. J. Gabe, Y. LePage, J. P. Charland, F. L. Lee, P. S. White, J. Appl. Crystallogr. 1989, 22, 384-385.

[20] Y. Wang, K. Angermund, R. Goddard, C. Kruger, J. Am. Chem. Soc. 1987, 109, 587-589.

[21] International Tables for X-Ray Crystallography, Vol. IV, Kynoch, Birmingham (UK), 1974.

[22] T. Koritsanszky, S. Howard, T. Richter, Z. Su, P. R. Mallinson, N. K. Hansen, XD: Computer program package for multipole refinement and analysis of electron densities from X-ray diffraction data, Free University of Berlin (Germany), 1996.

[23] a) N. K. Hansen, P. Coppens, Acta Crystallogr. Sect. A 1978, 34, $909-$ 921; b) P. Coppens, X-ray Charge Densities and Chemical Bonding, Oxford University Press, Oxford, 1997.

[24] A. Volkov, C. Gatti, Y. Abramov, P. Coppens, Acta Crystallogr. Sect. A 2000, 56, 252.

[25] A. K. Rappe, T. A. Smedley, W. A. Goddard, III, J. Phys. Chem. 1981, $85,2607-2611$

[26] A. J. H. Wachters, J. Chem. Phys. 1970, 52, 1033-1036.
[27] S. J. Vosko, L. Wilk, M. Nusair, Can. J. Phys. 1980, 58, 1200-1211.

[28] Gaussian 98 (Revision A.7), M. J. Frisch, G. W. Trucks, H. B. Schlegel, G. E. Scuseria, M. A. Robb, J. R. Cheeseman, V. G. Zakrzewski, J. A Montgomery, R. E. Stratmann, J. C. Burant, S. Dapprich, J. M. Millam, A. D. Daniels, K. N. Kudin, M. C. Strain, O. Farkas, J. Tomasi, V. Barone, M. Cossi, R. Cammi, B. Mennucci, C. Pomelli, C. Adamo, S. Clifford, J. Ochterski, G. A. Petersson, P. Y. Ayala, Q. Cui, K. Morokuma, D. K. Malick, A. D. Rabuck, K. Raghavachari, J. B. Foresman, J. Cioslowski, J. V. Ortiz, B. B. Stefanov, G. Liu, A. Liashenko, P. Piskorz, I. Komaromi, R. Gomperts, R. L. Martin, D. J. Fox, T. Keith, M. A. Al-Laham, C. Y. Peng, A. Nanayakkara, C. Gonzalez, M. Challacombe, P. M. W. Gill, B. G. Johnson, W. Chen, M. W. Wong, J. L. Andres, M. Head-Gordon, E. S. Replogle, J. A. Pople, Gaussian, Inc., Pittsburgh PA, 1998.

[29] C. Lee, W. Yang, R. G. Parr, Phys. Rev. B 1988, 37, 785.

[30] A. D. Becke, J. Chem. Phys. 1993, 98, 5648.

[31] R. F. W. Bader, AIMPAC: a set of programs for the theory of atoms in molecules, McMaster University, Hamilton, Ontario (Canada L8S 4M1), 1994.

[32] A. E. Reed, F. Weinhold, J. Chem. Phys. 1985, 83, 1736-1940.

[33] A. E. Reed, F. Weinhold, J. Am. Chem. Soc. 1980, 102, 7211-7218.

[34] A. E. Reed, R. B. Weistock, F. Weinhold, J. Chem. Phys. 1985, 83, $735-746$.

[35] A. E. Reed, L. A. Curtiss, F. Weinhold, Chem. Rev. 1988, 88, 899-926.

[36] P. O. Löwdin, Phys. Rev. 1955, 97, 1474-1489.

[37] a) L. Pauling, J. Am. Chem. Soc. 1931, 53, 1367-1400; b) C. A. Coulson, Valence, 2nd ed., Oxford University Press, London, 1952.

[38] R. F. W. Bader, J. Phys. Chem. 1998, A102, 7314-7323.

[39] a) R. F. W. Bader, T.-H. Tang, Y. Tal, F. W. Biegler-König, J. Am. Chem. Soc. 1982, 104, 940 -946; b) R. F. W. Bader, T. Slee, D. Cremer, E. Kraka, J. Am. Chem. Soc. 1983, 105, 5061-5068; c) D. Cremer, E. Kraka, Croat. Chem. Acta 1984, 57, 1259-1281.

[40] a) Y. Abramov, Acta Crystallogr. Sect. A 1997, 53, 264-272; b) E. Espinosa, E. Molins, C. Lecomte, Chem. Phys. Lett. 1998, 285, 170 173.

[41] Y. Aray, J. Rodriguez, D. Vega, E. N. Rodriguez-Arias, Angew. Chem. 2000, 112, 3968-3971; Angew. Chem. Int. Ed. 2000, 39, 3810-3813.

[42] A. Volkov, C. Gatti, TOPXD 2.0 manual, Department of Chemistry, State University of New York at Buffalo, Buffalo, New York, 2000.

[43] M. Souhassou, R. H. Blessing, J. Appl. Crystallogr. 1999, 32, 210-217.

Received: October 4, 2001 [F3590] 